\title{
Legged Robotic Systems
}

\author{
Giuseppe Carbone \& Marco Ceccarelli
}

\section{Introduction}

Walking machines have been attempted since the beginning of the technology of transportation machinery with the aim to overpass the limits of wheeled systems by looking at legged solutions in nature. But only since the last part of the 20-th century very efficient walking machines have been conceived, designed, and built with good performances that are suitable for practical applications carrying significant payload with relevant flexibility and versatility.

In this chapter we have presented a survey of the variety of current solutions and prototypes of walking machines and we have illustrated fundamental characteristics and problems for their design and operation. The worldwide feasibility of walking machines is presented by discussing the activity at LARM: Laboratory of Robotics and Mechatronics in Cassino (Italy) as concerning with low-cost easy-operation solutions that can really make the walking machines available to non expert users for many applications.

\section{Walking in Nature}

Movement is a fundamental distinguishing feature of animal life. The locomotion over a surface by means of limbs or legs can be defined as walking whatever are the number of limbs or legs that are used. Different ways of walking have been achieved by the evolutionary process in nature. The vertebrate animals have a spinal column and one or two pairs of limbs that are used for the walking. These limbs are located beneath the body. Arthropoda animals including crustaceans, insects, centipedes, millipedes, symphylans, pauropodans and trilobites are characterized by a segmented body that is covered by a jointed external skeleton (exoskeleton), with paired jointed limbs on each segment so that they can have an high number of limbs. In this type of animals a stable walking can be achieved with a minimum of six limbs that are located in a side position with respect to the animal's body since they cannot use the flexibility of the spinal column for regulating the masses' positions during the walking.

A large variety of efficient mechanical and physiological designs have evolved in nature in order to fit with the characteristics of a given physical environment and different locomotion modes. Animals seem to have evolved to be as fast as possible, to have the best possible acceleration, maneuverability and endurance, and to have energy consumption as low as possible. However, these objectives are not always compatible with each others. For example tortoises are designed to walk with energy consumption as low as possible but they cannot be fast. Similarly, an animal that has been adapted to sprint as fast as possible, has not good endurance. Usually, nature evolution can be expected to have preferred 
compromises between the requirements of speed, endurance, and energy consumption. Thus, a wide range of different solutions can be found in nature.

The locomotion for a legged animal can be analyzed in term of three main components: the power source, the transmission system, the power outputs.

The power source is located in the muscles where chemical energy is converted in mechanical energy. The power outputs are the parts of an animal that are directly in contact with the environment and produces the motion. The transmission system transmits the mechanical energy from the muscles to the power outputs. For vertebrate animals this transmission system is composed of bones and articulations, and the power outputs are usually the feet.

Legged locomotion systems that have evolved in nature, show very good performances in terms of stability, payload capabilities, dynamic behavior. Thus, usually they are considered a very important source of inspiration for designing legged robotic systems mainly for aspects ranging from the mechatronic design to the path planning and gait generation. Several researchers have stressed these topics by using a multidisciplinary approach. For example, several studies have been addressed to the transmission system of vertebrate legged animals from a kinematic point of view. In fact, bones and articulations can be easily modeled as links and joints of a kinematic architecture. Examples of for biped, quadruped and hexapod locomotions in nature are shown in Fig.1 to 5 with their simplified kinematic architectures. Those animals have been and still are inspiration both for design and operation of walking legged systems. In the following main features are reported for each animal but more details can be and have been considered in inspiring/mimicking for walking legged systems.

In particular, Fig.1a) shows the most attractive biped locomotion: a human being. Figure 1b) also shows a kinematic scheme of a human being. Each leg in Fig.1b) can be considered to have seven degrees of freedom. In a human being the muscles are distributed so that the forward motion is more efficient than the backward and side motion. The maximum speed is about $11.0 \mathrm{~m} / \mathrm{s}$ during a 100 meter run. The average weight of a human being is $650 \mathrm{~N}$. Main characteristics of the human being in terms of biped locomotion are reported in Tab. 1 in which data refer to general common operation. Maximum values of performances strongly depend on situations, environments of life, and training and they can reach even values higher then in Tab.1.

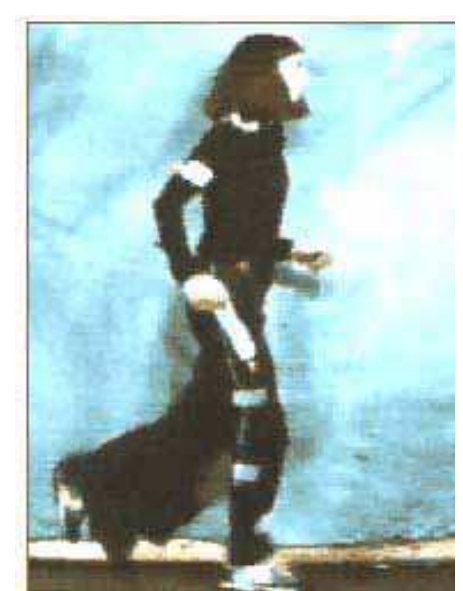

a)

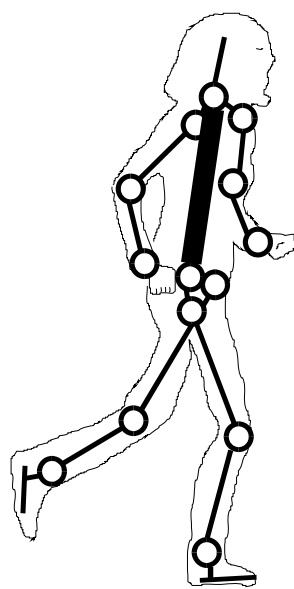

b)

Figure 1. Biped locomotion by a human being: a) a picture ${ }^{1}$; b) a kinematic scheme

\footnotetext{
${ }^{1}$ All the pictures have been taken from webpages that are available in internet.
} 
Figure 2a) and b) show an ostrich and a simplified kinematic scheme of its two legs, respectively. Its kinematic scheme is similar to the human being and each limb can be considered to have seven degrees of freedom. Even in this case the muscle distribution facilitates the forward motion. The average weight is 1,800 N. but the mass distribution provides a lower center of mass and a better attitude to run compared with humans. Even if ostriches can be classified as birds they have lost their ability to fly but they can still escape predators with their fast running at a maximum speed of $19.4 \mathrm{~m} / \mathrm{s}$ during a 800 meter run. Main characteristics of the ostrich are reported in Table 1.

It is worth noting that the stability of a body in the space can be guaranteed with a minimum of three points in contact with the ground. It this case, the walking stability is obtained if the projection of the center of mass of the body lays within the area obtained by connecting the contact points. However, the biped locomotion can provide only one or two limbs in contact with the ground. Thus, biped locomotion cannot be considered as statically stable. Indeed, bipeds do not fall down since they can control the posture of their upper body in order to keep the balance in dynamic conditions. This require clever control strategies based on the feedback of several vision, auditory, and tactile sensors. In addition, a control of the compliance through spinal cord, muscles, and feet is used for the compensation of dynamic effects. Beside the complexity of biped stable walking (but also run), the biped structure show the most flexible locomotion in term of obstacle avoidance and fast reshaping of walking mode.

Figure 3 a) and b) show a young child as an example of quadruped locomotion and a simplified kinematics scheme of his four limbs, respectively. In this case, feet and arms are both used as limbs for the locomotion. A clever example of using arms like legs can be recognized in monks, which are often considered of inspiration for robotic systems with variable capabilities.

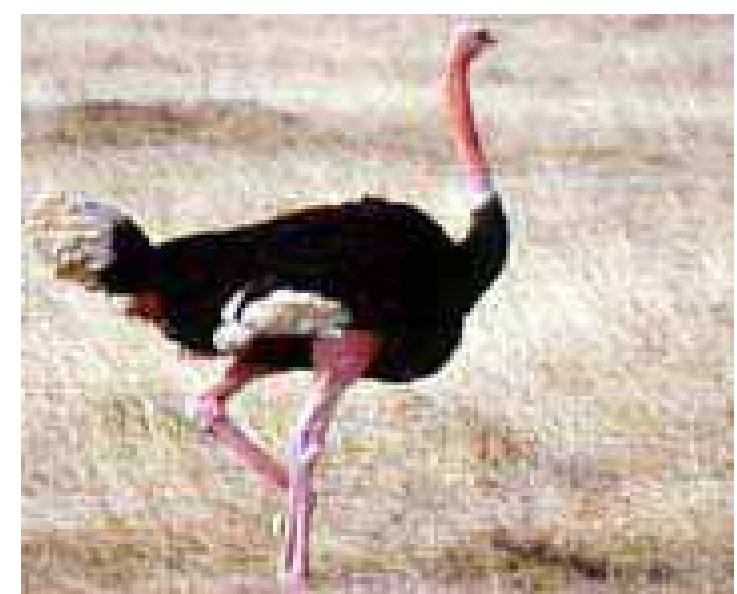

a)

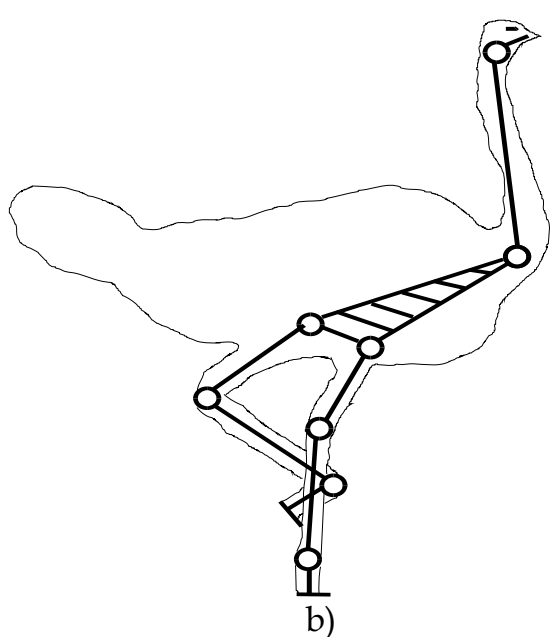

$\frac{1}{b)}$

Figure 2. Biped locomotion by an ostrich: a) a picture; b) a kinematics scheme

This type of locomotion is used by human being at their first months of life since it is statically stable and requires less sensory feedback. It is worth noting that a young child can not achieve a very efficient quadruped motion since the human arms are not equipped with proper muscles. Thus, he starts to use a biped locomotion as soon as his body and brain are capable of keeping the equilibrium in dynamic conditions. More characteristics of a young child in terms of quadruped locomotion are reported in Table 1.

Figure 4a) and b) show a horse and a simplified kinematic scheme of its four limbs, 
respectively. In the case of horses, the quadruped locomotion can be considered very efficient. In fact, they can be considered among the fastest legged animals with a maximum speed of $21.1 \mathrm{~m} / \mathrm{s}$ during a 800 meter run. Moreover, they show a good payload capacity and attitude to jumping. More details are reported in Table 1.

Figures 5 and 6 shows two examples of hexapod locomotion: a spider and a cockroach and a simplified kinematic scheme of their six limbs, respectively. The use of six limbs provide to these animals a very good ability of movements in rough terrain and also a surprisingly high payloads capability.

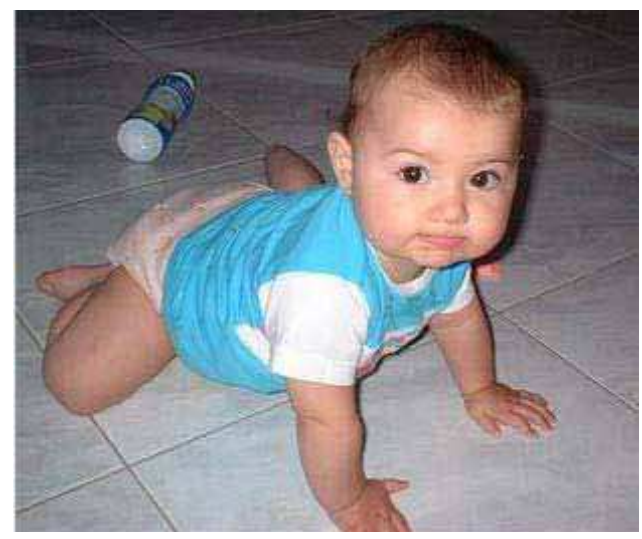

a)

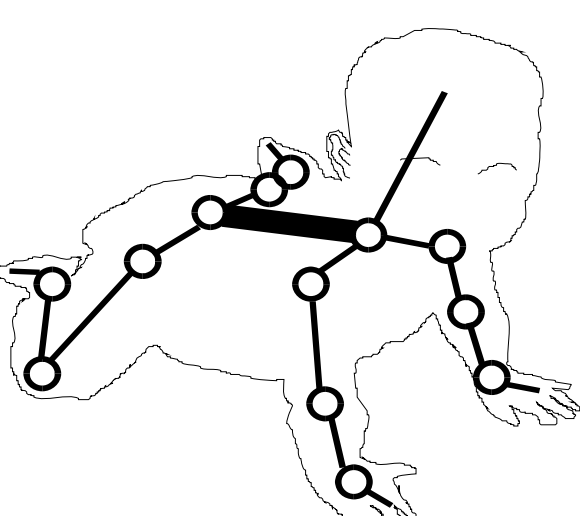

b)

Figure 3. Quadruped locomotion by a young child: a) a picture; b) a kinematic scheme

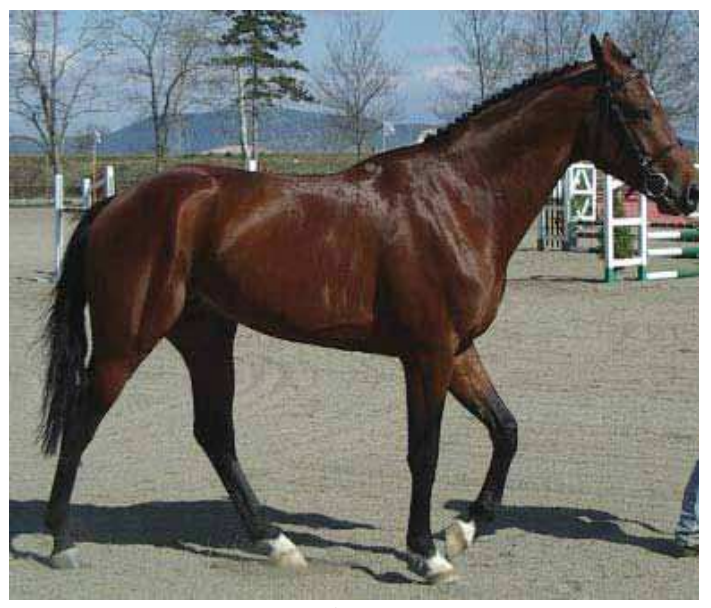

a)

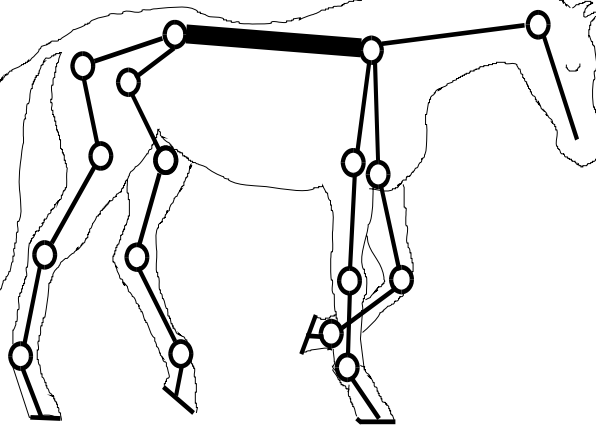

b)

Figure 4. Quadruped locomotion by a horse: a) a picture; b) a kinematic scheme

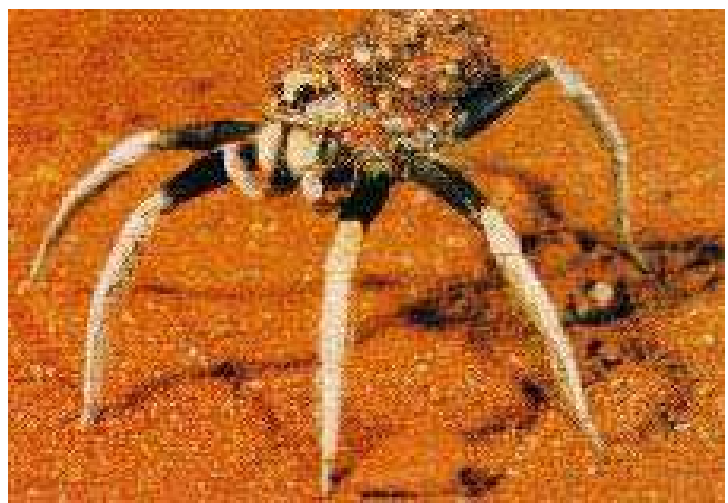

a)

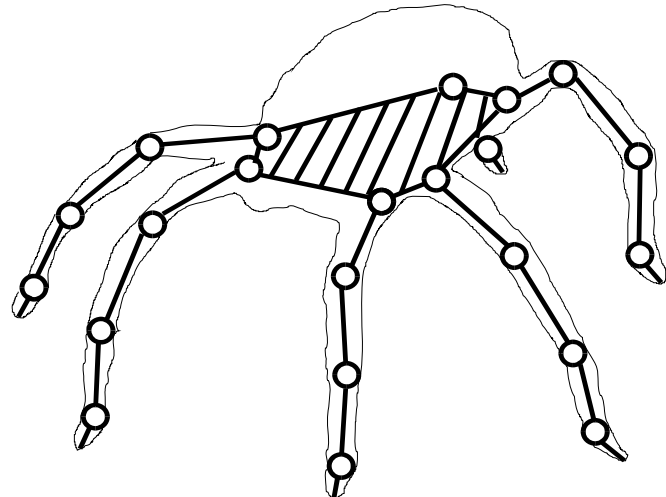

b)

Figure 5. Hexapod locomotion by a spider: a) a picture; b) a kinematic scheme 


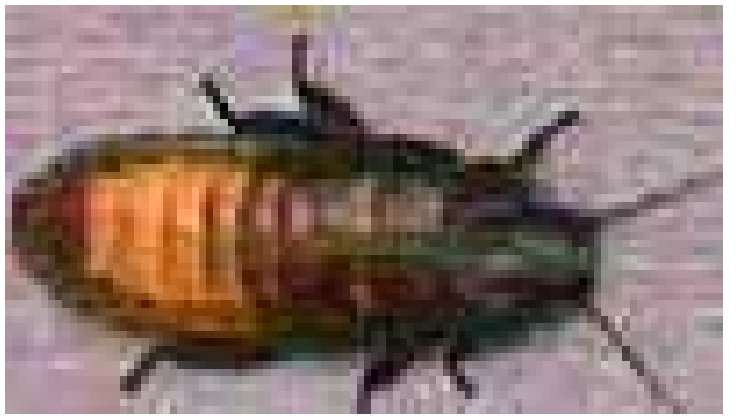

a)

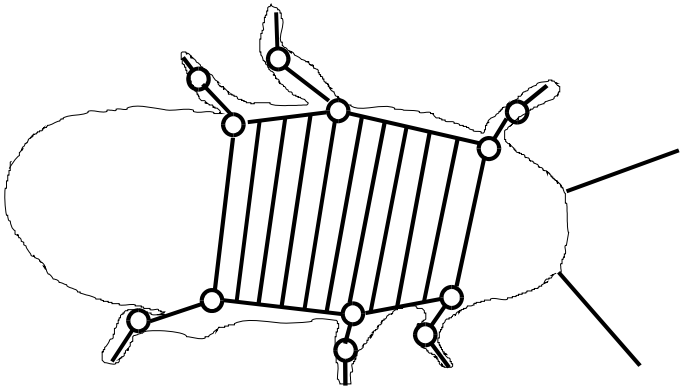

b)

Figure 6. Hexapod locomotion by a cockroach: a) a picture; b) a kinematic scheme

For example, a giant cockroach can move a weight of even 800 times its weight. Nevertheless, the hexapod locomotion is mainly used by animals having small size and weight. This is probably due to the complexity of distribution of muscles for all the limbs and also for the complexity of the control strategy for walking modes.

\begin{tabular}{|c|c|c|c|c|c|c|c|}
\hline Name & $\begin{array}{c}\text { Size } \\
{[\mathrm{m}]}\end{array}$ & $\begin{array}{c}\text { Weight } \\
{[\mathrm{N}]}\end{array}$ & $\begin{array}{c}\text { Max. Speed } \\
{[\mathrm{m} / \mathrm{s}]}\end{array}$ & $\begin{array}{c}\text { Step size } \\
{[\mathrm{m}]}\end{array}$ & $\begin{array}{c}\text { Step height } \\
{[\mathrm{m}]}\end{array}$ & $\begin{array}{c}\text { Payload } \\
{[\mathrm{N}]}\end{array}$ & Photo \\
\hline Human being & $1.7 \times 0.5 \times 0.3$ & 650 & 11.0 & 0.6 & 0.3 & 500 & Fig.1 \\
\hline Ostrich & $2.5 \times 1.6 \times 0.8$ & 1,800 & 19.4 & 0.6 & 0.6 & 500 & Fig.2 \\
\hline Young child & $0.4 \times 0.2 \times 0.2$ & 100 & 0.5 & 0.1 & 0.05 & 5 & Fig.3 \\
\hline Horse & $1.6 \times 2.0 \times 0.6$ & 4,500 & 21.1 & 0.6 & 0.6 & 1,000 & Fig.4 \\
\hline Spider & $0.1 \times 0.1 \times 0.1$ & 1 & 1.5 & 0.03 & 0.03 & 100 & Fig.5 \\
\hline cockroach & $0.05 \times 0.05 \times 0.05$ & 0.5 & 1.3 & 0.02 & 0.02 & 400 & Fig.6 \\
\hline
\end{tabular}

Table 1. Main characteristics of the animals shown in Figs.1 to 6. (Values, when not available, have been estimated from size, kinematic architecture, and mobility range)

\section{Existing Walking Machines}

The kinematic models of Fig.1 to 6 have inspired and still inspire the mechatronic design and operation for several biped, quadruped and hexapod walking machines.

In the recent past several walking machines have been developed for several different purposes mainly in research laboratories. Significant examples of walking machines are shown in Fig.7 to 13:

- Honda robot ASIMO, Fig.7a);

- Sony robot SDR-4X, , Fig.7b);

- Waseda robot WABIAN-RV, Fig.7c);

- Waseda biped locomotor WL-16R, Fig.8;

- CSIC robot RIMHO2, Fig.9a);

- Ambulatory Robotic Lab. robot Scout II, Fig.9b);

- Hirose \& Yoneda Robotic Lab. robot TITAN VIII, Fig.10a);

- Intelligent Machines and Special Robotics Institute robot WorkPartner, Fig.10b);

- Chiba University COMET II, Fig.11a);

- Ambulatory Robotic Lab. robot Rhex, Fig.11b);

- Plustech Ltd. Walking Forest Machine, Fig.12a);

- Ohio State University Adaptive Suspension Vehicle, Fig.12b);

- Sony robot AIBO, Fig.13. 
In Tab.2 main characteristics are reported with values that are indicative of design and operation performances. In the following, synthetic descriptions are discussed to outline basic problems and solutions that are available in the current state of walking machines.

ASIMO (Advanced Step in Innovative MObility), Fig.7a), has been built at Honda in the year 2000. It is a biped humanoid robot having a total of 26 degrees of freedom. Its size, weight and ranges of mobility have been conceived to mimic as much as possible a human child and move freely within the human living environment. ASIMO is able to ascend and descend stairs, to walk by following different patterns, to avoid obstacles, to grasp objects, to interact with humans by means of sound and image recognition. It is equipped with on board batteries for a continuous operating time of about $30 \mathrm{~min}$.

SDR-4X (Sony Dream Robot version 4X), Fig.7b) has been built at Sony in the year 2002. It is a small biped humanoid robot that has been conceived for entertainment purposes. It has a total of 38 degrees of freedoms. It can walk on irregular (up to 10mm) and tilted surface (up to 10 degrees), and can prevent falling over when an external pressure is applied. Its software includes real time generator of walking patterns in order to adapt its behavior to various situations. Image and sound recognition features have been also implemented. It is equipped with on board batteries for a continuous operating time of 2 hour approximately.

WABIAN-RV (Waseda Biped humANoid Refined V), Fig.7c), is a biped humanoid robot that has been developed for human-robot cooperation work at Waseda University, in Tokyo in the year 2002. It is the last version of WABIAN series started since 1972. It has a total of 43 dofs. The size and motion range of each link has been designed to be as human like as possible. By using WABIAN series, a variety of walking has been achieved such as dynamic forward and backward walking, marching in place, dancing, carrying a load, and emotional walking. Its software includes an on-line pattern generator, image and sound recognition features. It requires an external power supply.

WL-16R (Waseda-Leg No.16 Refined), Fig.8, has been designed at Waseda University in Tokyo in the year 2004 for practical use as a multi-purpose biped locomotor for robotic systems. It is composed of two 6-dof legs with parallel architecture design. It can be seen as a bipedal robot with only lower-limbs that can dynamically walk independently. Its upper body can be developed by users according to their use purposes.

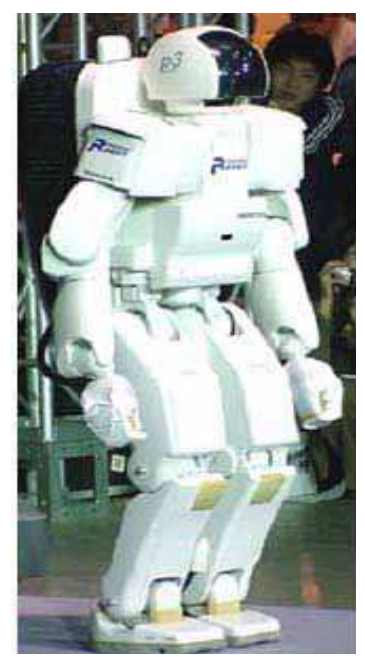

a)

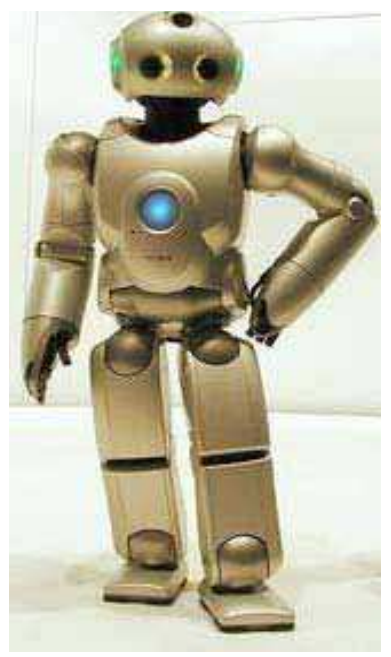

b)

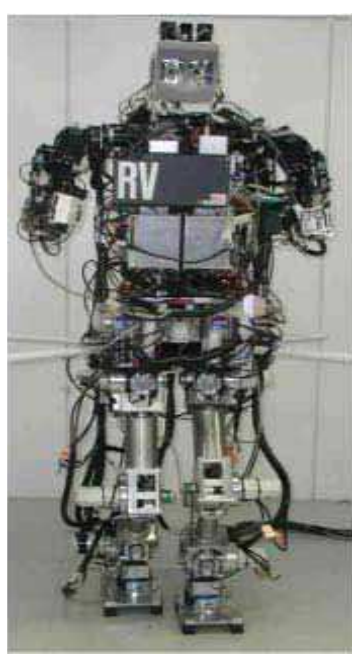

c)

Figure 7. Examples of current biped walking machines: a) Honda robot ASIMO; b) Sony Robot SDR-4X, c) Waseda robot WABIAN-RV 


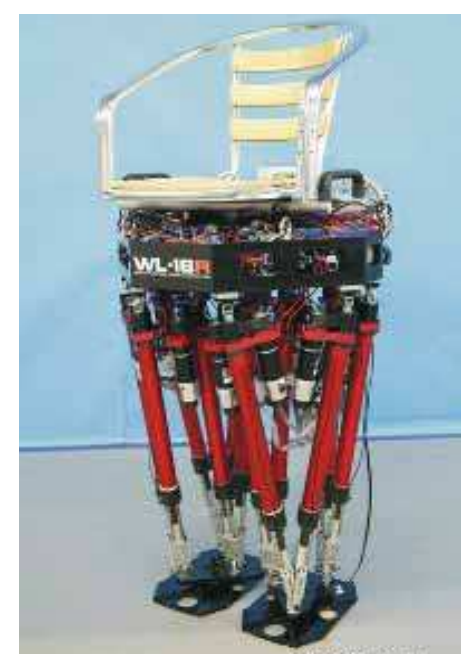

a)

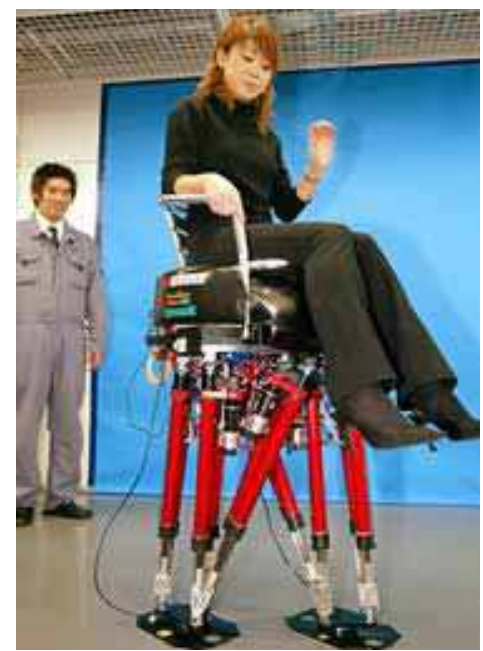

b)

Figure 8. Waseda biped locomotor WL-16R with non anthropomorphic legs: a) a side view; b) carrying a human

In particular, it would be applicable to the welfare field as a walking wheelchair or as a walking support machine that is able to walk up and down stairs carrying or assisting a human. It is equipped with an on board Nickel Metal Hydride battery for a continuous operating time of 1 hour approximately. The RIMHO II walking robot, Fig.9a), has been developed from the Industrial Automation Institute-CSIC and the CIEMAT in Madrid since 1993. It is a quadruped-walking machine of the insect type. Its four legs are based on a three dimensional Cartesian pantograph mechanism. The RIMHO walking robot can perform both discontinuous and wave gaits over irregular terrain including slopes and stairs, and has been tested also over natural terrain as shown in Fig.9a).

SCOUT II, Fig.9b) has been developed at Ambulatory Robotic Laboratory in Montreal since 1998. It is composed of four legs. Each leg has one active degree of freedom only. A spring and a passive knee are added in order to provide two additional passive degrees of freedom for each leg. These passive degrees of freedom make the Scout II capable of achieving dynamic running similar to gallop and trot. SCOUT II is fully autonomous having on board power, computing and sensing. Other features include an on board pantilt camera system and laser sensors.

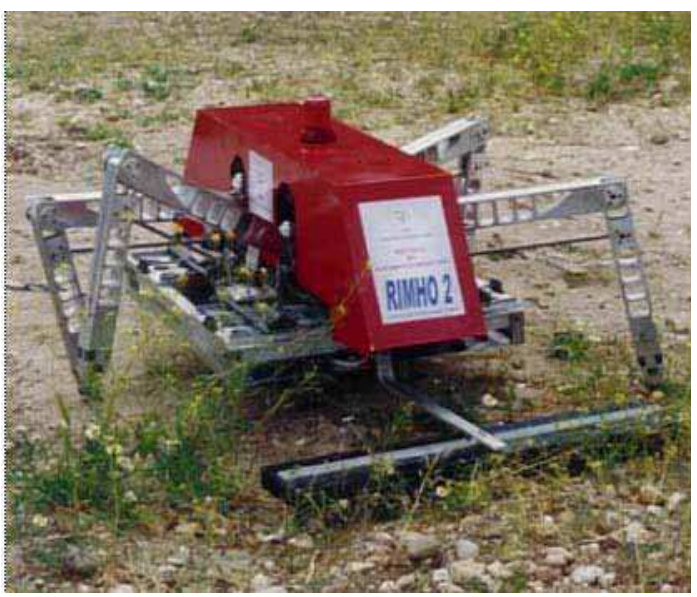

a)

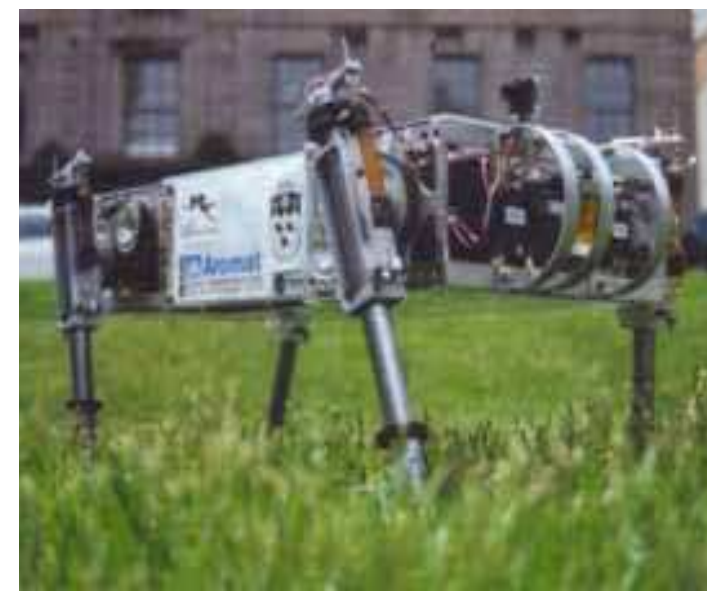

b)

Figure 9. Examples of four legged walking machines: a) RIMHO2; b) Scout II 


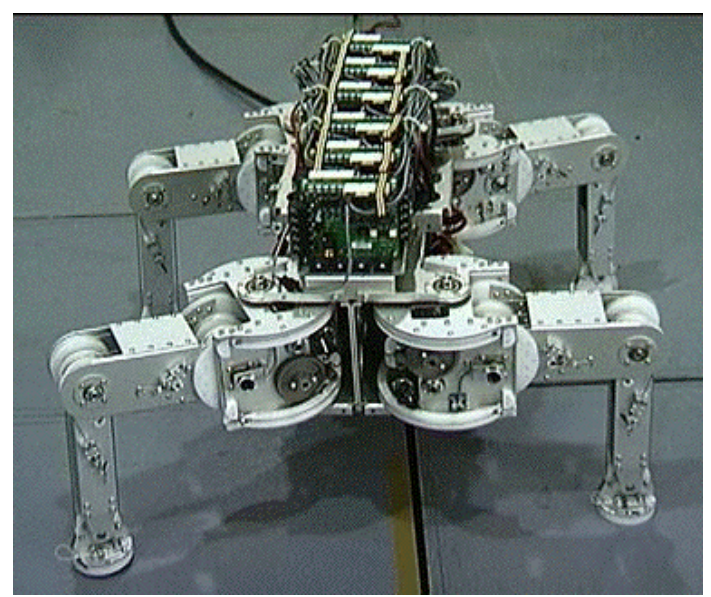

a)

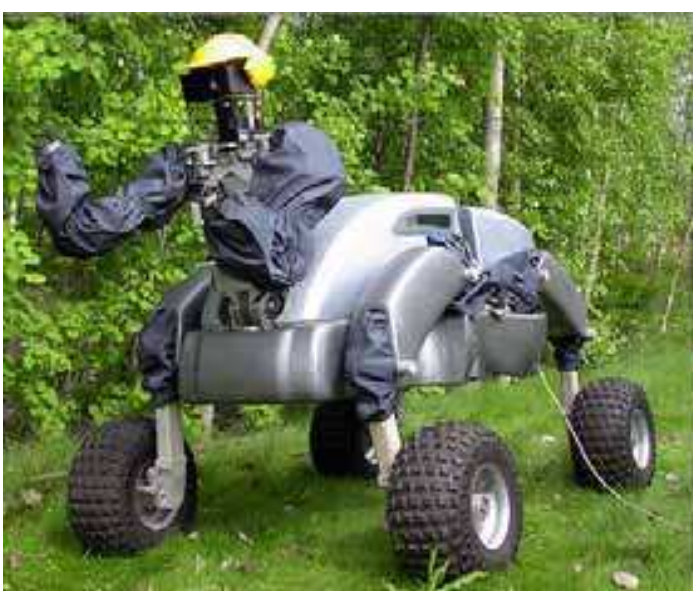

b)

Figure 10. Examples of four legged walking machines with wheels: a) TITAN VIII; b) WorkPartner

TITAN VIII, Fig.10a) has been built at Hirose \& Yoneda Robotic Lab. in Tokyo in the year 1996. TITAN VIII is a walking machine having four legs.

The leg mechanism is composed of a planar 2 degrees of freedom mechanism and a rotating mechanism which rotates this planar mechanism. So this leg mechanism has 3DOF. Wires and pulleys are used for the power transmission within the leg. The feet of TITAN VIII can be used also as wheels in order to achieve faster motion on flat surfaces.

WorkPartner, Fig.10b), is a four leg mobile robot that has been built at the Intelligent Machines and Special Robotics Institute in Helsinki in 2000. The locomotion system of WorkPartner is hybrid. In fact, it is possible to move by means of legs only, with legs and wheels powered at the same time or with wheels only. WorkPartner is equipped with two arms having 3 degrees of freedom arms and a two-degree of freedom camera head. Several sensors have been installed on board such as potentiometers, force sensors, inclinometers, gyro, accelerometers, ultra sonic sensors, laser scanner. A combustion engine and four batteries are also installed on board for a continuous operating time of 30 min. approximately.

COMET II has been developed at Chiba University in Tokyo in 2002. It can be used as fully autonomous system or teleoperated by a human for demining tasks. It is equipped with two manipulators that are used for mine detection and grass cutting.

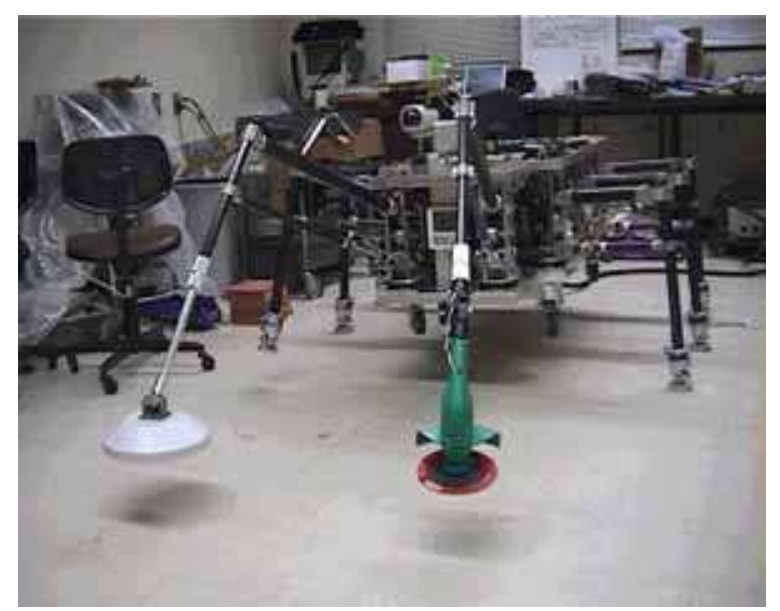

a)

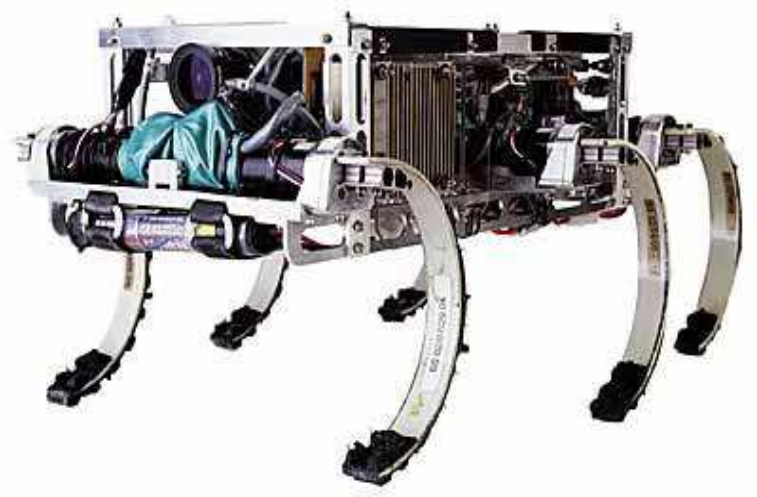

b)

Figure 11. Examples of six legged walking machines: a) COMET II; b) RHex 
Several sensors are installed on board such as metal detector, radar, cameras, force sensors, potenziometers.

The implemented software includes obstacle avoidance features. Power supply is provided by a gasoline power generator for outdoor operation or from an external power supply for indoor laboratory tests.

RHEx robot, Fig.11b), has been developed at Ambulatory Robotic Lab. in Montreal since 1999. It has six legs with only one degree of freedom. The leg has a very simple design. It is made by heat shaped Delrin rods and it has a soft feet at its free end. RHEx robot is equipped with gyros accelerometers, and optical encoders. It is capable of achieving a wide variety of dynamically dextrous tasks, such as walking, running, leaping over obstacles, climbing stairs. Two batteries are on board installed for a continuous operating time of about $10 \mathrm{~min}$.

The Walking Forest Machine, Fig.12a), has been developed at Plustech Ltd. since 1995 for outdoor forest harvesting tasks. It is composed of six articulated legs. It can move forward, backward, sideways and diagonally. It can also turn in place and step over obstacles. Depending on the irregularity of the terrain, the operator can adjust both the ground clearance of the machine and height of each step. The operator-friendly controls are incorporated in a joystick that controls direction of movement, traveling speed, step height and gait, and the ground clearance.

Adaptive Suspension Vehicle, Fig.12b), has been developed at Ohio State University since early 80's. It is composed of six articulated legs. Each leg has three active degrees of freedom. It has been designed for walking on rough terrains by carrying a maximum load of $2156 \mathrm{~N}$. It is equipped with gyros, laser sensors and a computer vision system that is used for adapting the gait to the environment. It can work either in teleoperated or operator-on-board mode by using active compliance control algorithms.

AIBO robot is a four legged robot for entertainment purposes. It has been developed by Sony since early 90's. It has evolved though several prototypes with different performance and shape. Figure 13 shows a version that is called ERS7 and is avaliable on the market since 2003 at a price of about 2000 Euros. This version has four legs with three degrees of freedom each. It is equipped with two microphones, a speaker, touch sensors, infrared sensors, accelerometers that provide AIBO with very high human-robot interaction capabilities. Rechargable batteries are on board installed allowing for a continuous operating time of 1.5 hours, approximately.

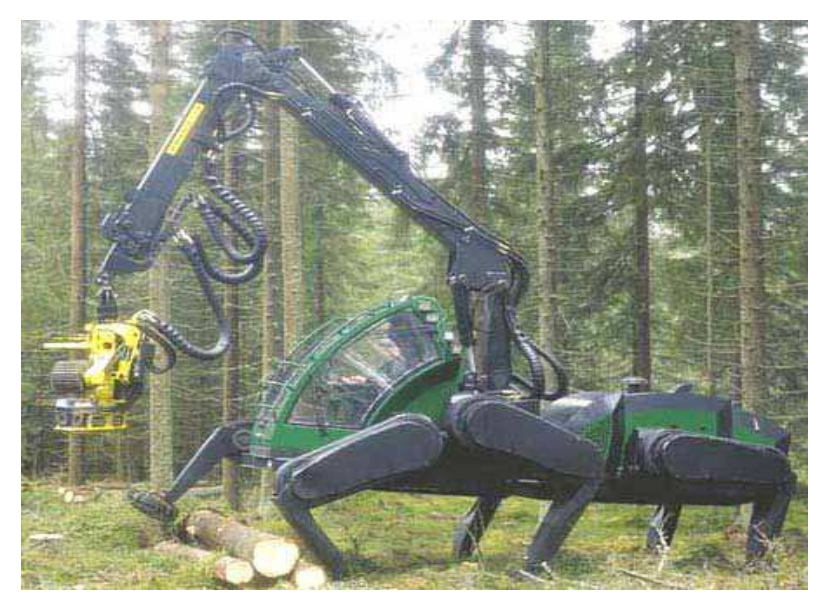

a)

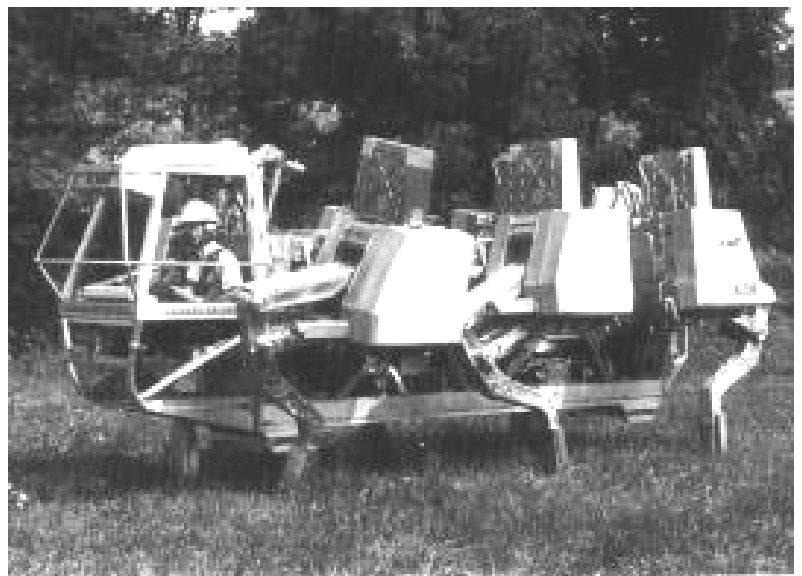

b)

Figure 12. Examples of six legged walking machines for outdoor applications: a) Walking forest machine; b) Adaptive Suspension Vehicle. 
The reported examples in Figs.7 to 13 give an illustrative view of the variety of walking systems that have been developed all around the world with different solutions for different applications. It is worth noting that most of them (with the exception of AIBO) are not yet available in the market but they are under further development in Research Labs.

\begin{tabular}{|c|c|c|c|c|c|c|c|}
\hline Name & $\begin{array}{c}\text { Size } \\
{[\mathrm{m}]}\end{array}$ & Weight $[\mathrm{N}]$ & $\begin{array}{c}\text { Max. Speed } \\
{[\mathrm{m} / \mathrm{s}]}\end{array}$ & $\begin{array}{c}\text { Step size } \\
{[\mathrm{m}]}\end{array}$ & $\begin{array}{c}\text { Step height } \\
{[\mathrm{m}]}\end{array}$ & $\begin{array}{c}\text { Payload } \\
{[\mathrm{N}]}\end{array}$ & Photo \\
\hline ASIMO & $1.2 \times 0.4 \times 0.5$ & 520 & 0.4 & 0.3 & 0.1 & 5 & Fig.7a $)$ \\
\hline SDR-4X & $0.6 \times 0.3 \times 0.2$ & 70 & 0.3 & 0.1 & 0.02 & 0 & Fig.7b) \\
\hline WABIAN-RV & $1.8 \times 0.4 \times 0.6$ & 1,300 & 0.3 & 0.3 & 0.1 & 10 & Fig.7c) \\
\hline WL-16 & $1.3 \times 0.6 \times 0.6$ & 620 & 0.3 & 0.3 & 0.1 & 600 & Fig.8 \\
\hline RIMHO2 & $0.7 \times 0.7 \times 0.3$ & 650 & 0.1 & 0.3 & 0.1 & 0 & Fig.9a) \\
\hline Scout II & $0.4 \times 0.4 \times 0.4$ & 270 & 1.5 & 0.1 & 0.1 & 5 & Fig.9b) \\
\hline TITAN VIII & $0.6 \times 0.3 \times 0.4$ & 190 & 0.2 & 0.2 & 0.2 & 70 & Fig.10a) \\
\hline WorkPartner & $1.4 \times 1.2 \times 1.2$ & 2,300 & 1.94 & 0.5 & 0.3 & 100 & Fig.10b) \\
\hline COMET II & $1.4 \times 0.6 \times 0.6$ & 1,000 & 0.1 & 0.2 & 0.3 & 200 & Fig.11a) \\
\hline RHex & $0.5 \times 0.2 \times 0.1$ & 70 & 0.4 & 0.1 & 0.2 & 0 & Fig.11b) \\
\hline A.S.V. & $5.2 \times 2.4 \times 3.0$ & 32,000 & 2.3 & 0.5 & 0.3 & 2156 & Fig.12a) \\
\hline W.F.M. & $7.4 \times 2.7 \times 3.7$ & 34,000 & 2.0 & 0.5 & 0.4 & 2000 & Fig.12b) \\
\hline AIBO & $0.2 \times 0.3 \times 0.3$ & 16.5 & 0.3 & 0.1 & 0.1 & 0 & Fig.13 \\
\hline
\end{tabular}

Table 2. Main characteristics of walking machine prototypes of Figs.7-13. (Values, when not available, have been estimated from size, mechanical design, and mobility range)

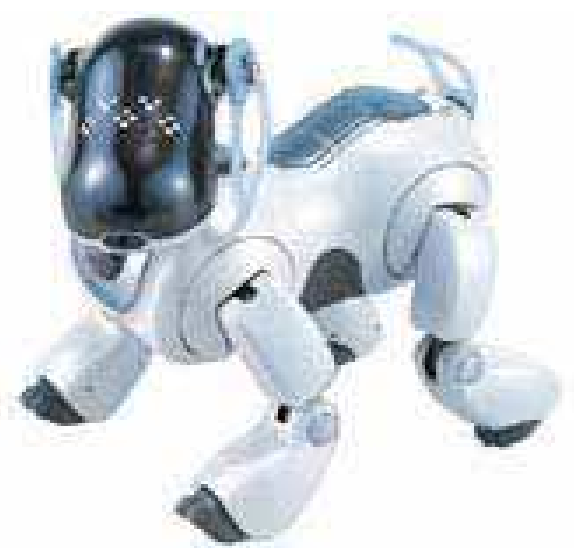

Figure 13. The low-cost four legged robot AIBO

Generally, legged systems can be slow and more difficult to design and operate with respect to machines that are equipped with crawlers or wheels. But, legged robots are more suitable for rough terrain, where obstacles of any size can appear. In fact, the use of wheels or crawlers limits the size of the obstacle that can be climbed, to half the diameter of the wheels. On the contrary, legged machines can overcome obstacles that are comparable with the size of the machine leg. Therefore, hybrid solutions that have legs and wheels at the same time have been also developed as shown for example in Fig.8c) and $\mathrm{d}$ ). This type of walking machines may range from wheeled devices to true walking machines with a set of wheels. In the first case, the suspensions are arms working like legs to overcome particularly difficult obstacles. In the second case wheels are used to enhance the speed when moving on flat terrain.

The advantage of the legged systems over the wheeled systems can be understood by looking at their kinematic capability and static performance. They can be deduced by the 
schemes of Fig.14 and 15 for legged and wheeled systems, respectively. In Fig.14 a biped system is represented by taking into account its weight $\mathrm{P}$, the weight PL of a leg, the forward acceleration a, the reaction force $\mathrm{R}$ at the ground, and the actuating torque CL for a leg. The geometry of the system is modeled trough the distances shown in Fig.14 among which $\mathrm{dL}$ represents the step capability and $\mathrm{h}$ is for the step height. The walking capability is given by the size of the distance $\mathrm{dL}$ that avoids falling of the system, together with motion capability for each leg that is given by the mobility range and actuating torque.

In particular, looking at the instantaneous equilibrium gives the computation of necessary conditions for a stable walking and the evaluation of the maximum step height. In the sagittal plane, the equilibrium can be expressed by

$$
\mathrm{R}_{\mathrm{h}}-\mathrm{P} \frac{\mathrm{a}}{\mathrm{g}}-\mathrm{PL} \frac{\mathrm{a}_{\mathrm{L}}}{\mathrm{g}} \geq 0 ; \mathrm{R}_{\mathrm{v}}-\mathrm{P}-\mathrm{PL} \geq 0 ; \mathrm{R}_{\mathrm{v}} \mathrm{dR}-\mathrm{PdP}-\mathrm{PL}(\mathrm{dP}+\mathrm{dL})-\mathrm{C}_{\mathrm{inS}} \geq 0
$$

where $R_{h}$ and $R_{v}$ are the horizontal and vertical components of $R ; C_{i n s}$ is the sagittal component of the inertial torque due to waist balancing movement.

The point $Q$ is assumed as the foot contact point about which the system will rotate in the possible fall. In the front plane the equilibrium can be expressed by

$$
\mathrm{R}_{1}-\mathrm{P} \frac{\mathrm{aS}}{\mathrm{g}} \geq 0 ; \mathrm{R}_{\mathrm{v}} \mathrm{pR}-\mathrm{PpP}-\mathrm{PL}(\mathrm{pP}+\mathrm{pL})-\mathrm{C}_{\text {inl }} \geq 0
$$

where $\mathrm{R}_{1}$ is the lateral component of $\mathrm{R}$; $\mathrm{C}_{\mathrm{inl}}$ is the lateral component of the inertial torque of waist balancing movement.

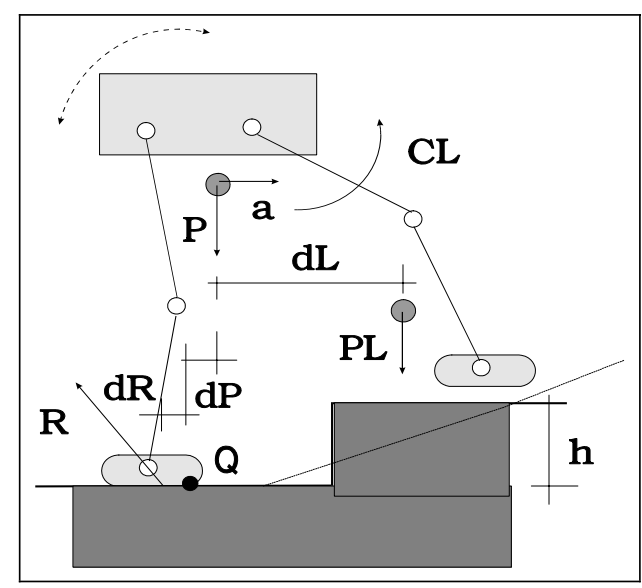

a)

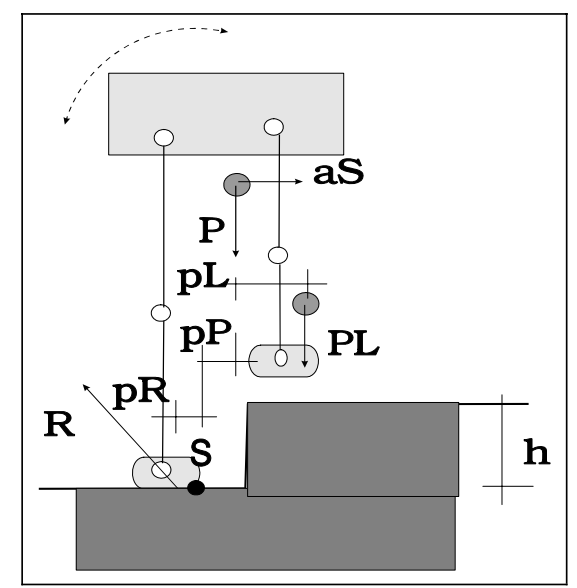

b)

Figure 14. A scheme for performance evaluation of biped walking machines: a) sagittal view; b) front view

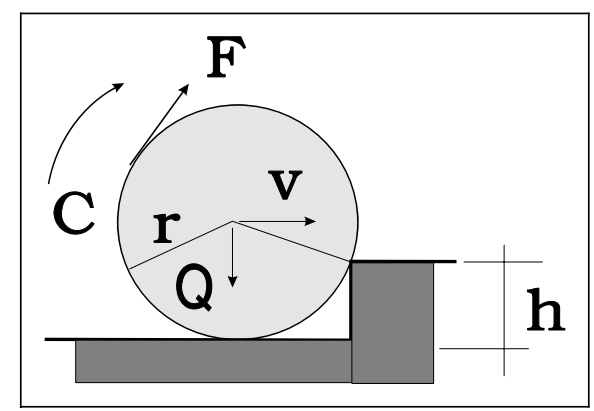

a)

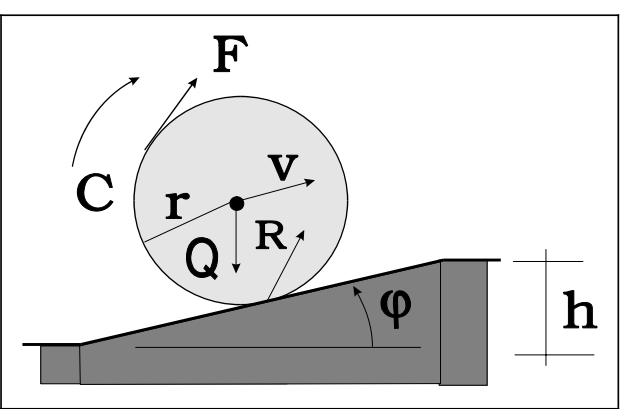

b)

Figure 15. A scheme for performance evaluation of wheeled machines 
The point $S$ is assumed as the foot contact point about which the system will rotate in the possible fall. The components $R_{h}$ and $R_{f}$ refer to friction actions at the foot contact area. By using Eqs.(1) and (2) is possible to compute conditions for design and operation in an environment with obstacles of height $h$.

From geometric viewpoint the obstacle/step of height $\mathrm{h}$ can be overpassed when the leg mobility gives

$$
11\left(1-\cos \phi_{1}\right)+12\left(1-\cos \phi_{2}\right)>\mathrm{h}
$$

in which 11 and 12 are the lenghts of leg links, whose angles $\phi_{1}$ and $\phi_{2}$ are measured with respect to a vertical line.

Similarly, for a wheeled system the instantaneous equilibrium can be expressed as referring to Fig.15 for the case a), in the form

$$
\mathrm{Q}-\mathrm{Rv}-\mathrm{N}=0 ; \mathrm{R}_{\mathrm{h}}-\mathrm{T}=0 ; \mathrm{C}(=\mathrm{Fr})=\mathrm{f}_{\mathrm{v}}(\mathrm{Q}+\mathrm{R})
$$

and for the case b) in the form

$$
\mathrm{Q} \cos \varphi=\mathrm{N} \quad \mathrm{Q} \sin \varphi=\mathrm{T} ; \quad \mathrm{C}=\mathrm{f}_{\mathrm{r}} \mathrm{r} \mathrm{Q} \cos \varphi
$$

with the condition for pure rolling (without sliding)

$$
\mathrm{T}<\mathrm{f} \mathrm{N}
$$

where $f$ is the sliding friction coefficient and $f_{v}(<<f)$ is the rolling friction coefficient; $R$ is the reaction force at the contact point in the step wedge; with its horizontal and vertical components $R_{h}$ and $R_{v} ; Q$ is the load and weight on the wheel axis; $C$ is the actuating torque due to force $F$ to maintain forward velocity $v$. The geometrical limits for overpassing an obstacle-step of height $\mathrm{h}$ through rolling a wheel can be expressed by

$$
\mathrm{r}>\mathrm{h}
$$

when the actuating torque acts only. Alternatively, a force will push upward the wheel or, as commonly used, the step is reshaped as an inclined plane, as shown in Fig.15b).

An intense activity is carried out not only for designing and prototyping walking machines but also for debating and exchanging information and experiences. The first activity is carried out in Research laboratories in Universities but also in Research Centres of governmental Institutions or Company Divisions. Very recently, some prototypes have been even commercialized and they are available in the market, like for example, AIBO robot for leisure/company applications or SDR-4X Sony robot for adverticing purposes. The success of these preliminary attempts of practical uses of walking machines stimulate more and more the development of systems for a variety of potential users.

Similarly entusiasmatic activity is that one with circulation and publication of results and information both on research activity and practical applications. This activity is mainly concentrated in forum like congress events or journal publications that can be considered also source for further reading and continuous updating of the State-of Art. The topic of walking machines is discussed in specific Conferences and Journals, but also as important section in more general events.

The following list is not exhaustive (also because new initiatives are continuously started) but it gives main sources and size of the publication activity on walking machines.

Conference Event Series:

International Conference on Climbing and Walking Robots (CLAWAR) 
IEEE-RAS International Conference on Humanoid Robots (HUMANOIDS)

International Conference of Intelligent Autonomous Systems (IAS)

IEEE International Conference on Systems, Man and Cybernetics (SMC)

CISM-IFToMM Symposium on Robot Design, Dynamics and Control (ROMANSY)

IEEE Mediterranean Conference on Control and Automation (MED);

International Conference on Advanced Robotics (ICAR)

IEEE/ASME International Conference on Advanced Intelligent Mechatronics (AIM)

World Congress in Mechanism and Machine Science (IFToMM)

IEEE International Conference on Robotics and Automation (ICRA)

IEEE-RSJ International Conference on Intelligent Robots and Systems (IROS)

ASME International Conference on Mechanisms and Robotics (MECH)

International Symposium on Multibody Systems and Mechatronics (MUSME)

International Workshop on Robotics in Alpe-Andria-Danube Region (RAAD)

ECCOMAS International Conference on Advances in Computational Multi-body Dynamics (Multibody Dynamics)

Technical - Scientific Journals:

International Journal of Humanoid Robotics (IJHR)

International Journal of Advanced Robotic Systems

Mechanism and Machine Theory

ASME Journal of Mechanical Design

International Journal Advanced Robotics

International Journal of Robotics Research

International Journal Robotica

Fuji International Journal of Robotics and Mechatronics

IEEE Transaction on Robotics

\section{Gait Analysis and Design Problems}

A gait is a pattern of locomotion characteristic of a limited range of speeds, described by quantities of which one or more change discontinuously at transitions to other motion patterns. A duty factor can be defined as the fraction of the duration of the stride, for which each foot is on the ground. In walking, each foot is on the ground for more than half the time, and in running for less than half the time. As speed increases, the duty factor falls gradually from about 0.65 in slow walks to about 0.55 in the fastest walks; but at the change to running it drops to around 0.35. Also the forces that are exerted on the ground can significantly change as speed increases and during the transition from a locomotion pattern to another.

There are several types of gaits in nature that are suitable for walking machines. Feasible gaits can be considered the following:

- human-like walking behavior;

- horse-like tolt behavior;

- horse-like trot behavior;

- horse-like pacing behavior;

- horse-like canter behavior;

- horse-like gallop behavior;

- crab-like walking behavior.

In the human-like walking behavior each foot leaves the ground at a different time. This type of gait can be achieved with two or more legs. Figure 16 shows the movements of 
limbs in a four leg walking also with the footfall formula representation. In footfall formula representation the limbs that are in contact with the ground surface are shown as black circles in a table in which the entries represent the possible foot contacts with the ground.

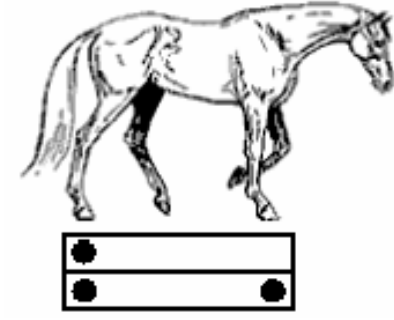

a)

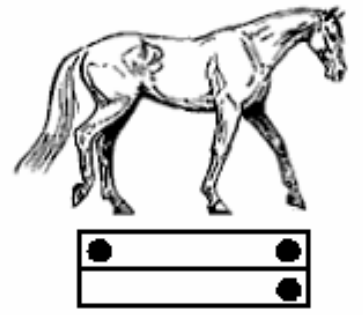

b)

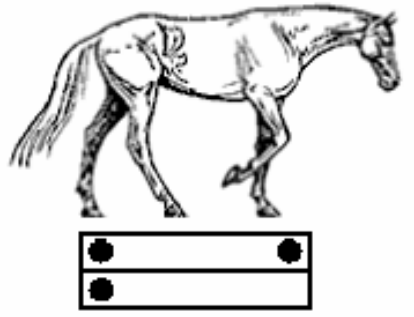

c)

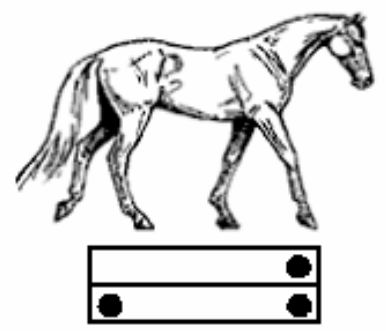

d)

Figure 16. Movements of limbs in a four legs walking with footfall formulas representation (black circles stands for the limbs in contact with the ground surface): a) first beat; b) second beat; c) third beat; d) fourth beat

A similar behavior is achieved in the horse-like tolt behavior, which is a running walk used when covering broken ground. This gait can be achieved with four legs.

In the horse-like trot behavior of Fig.17 the legs move in diagonal pairs, with a moment of suspension between each stride.

This type of gait can be achieved with four or more legs. Figure 17 shows the movements of limbs in a four legs trot also with the footfall formulas representation.

In the horse-like pacing behavior the legs of the same side move simultaneously. Thus, one has the two left legs or the two right legs in contact with the ground while the other two legs move forward simultaneously.

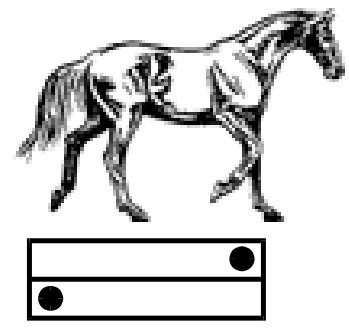

a)

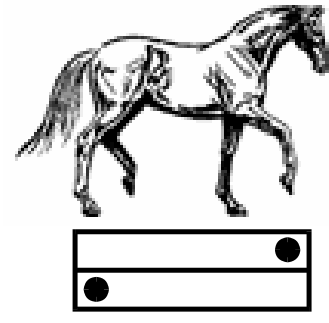

b)

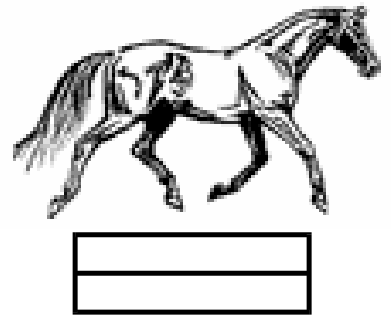

c)

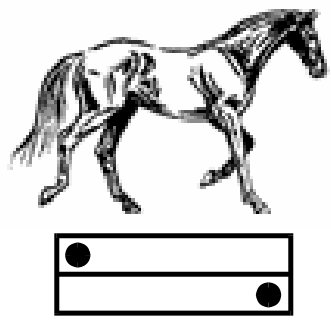

d)

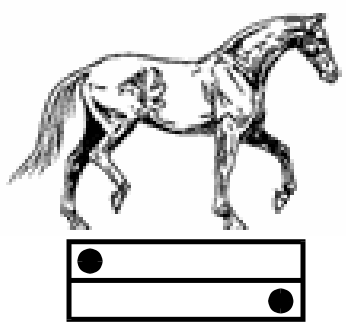

e)

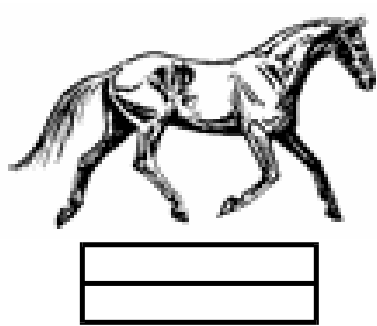

f)

Figure 17. Movements of limbs in a four legs trot with footfall formulas representation (black circles stands for the limbs in contact with the ground surface): a) first beat; b) first support phase; c) first suspension phase (all feet are off the ground); d) second beat; e) second support phase; $f$ ) second suspension phase 


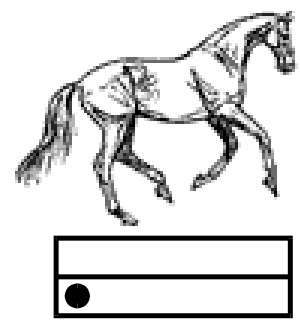

a)

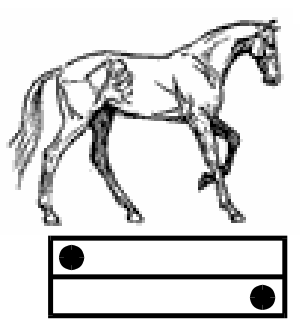

b)

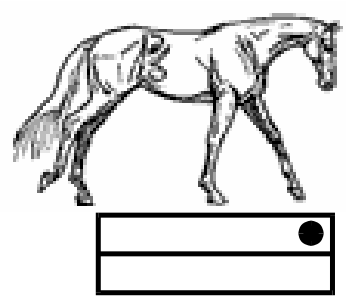

c)

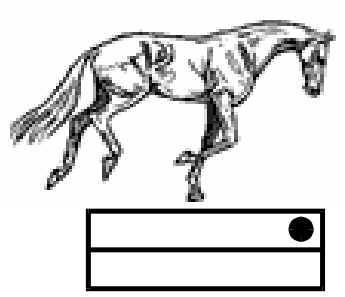

d)

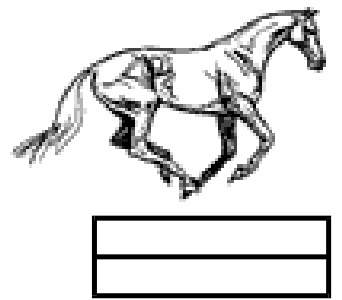

e)

Figure 18. Movements of limbs in a four legs canter with footfall formulas representation (black circles stands for the limbs in contact with the ground surface): a) first beat; b) second beat; c) third beat; d) fourth beat e) suspension phase (all feet are off the ground)

In the horse-like canter behavior in Fig.18 the legs move in the following 4 phases: an hind leg, the other hind leg together with the diagonal fore leg, the other fore leg, at this time there is a period where all four feet are off the ground. This type of gait can be achieved with four or more legs. Figure 18 shows the movements of limbs in a four legs canter also with the footfall formulas representation. In the horse-like gallop behavior in Fig.19 the legs move in the following 4 phases: an hind leg, the other hind leg, the diagonal fore leg, the other fore leg, at this time there is a period where all four feet are off the ground. This type of gait can be achieved with four or more legs. Figure 19 shows the movements of limbs in a four legs trot also with the footfall formulas representation.

There are also other horse-like gaits in which there are lateral movements. Crab-like walking behavior are similar to the human-like behavior but it is possible to have a lateral walking instead of forward or backward.

Increasing the number of limbs increases the number of feasible gaits, increases the flexibility of the motion but at the same time increases the complexity of the control for the coordination of the movements of each limb.

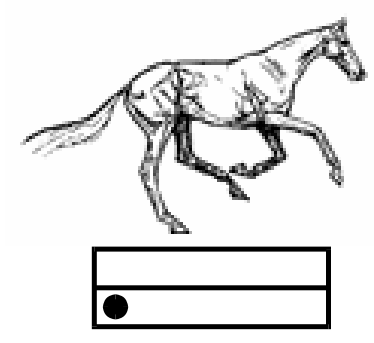

a)

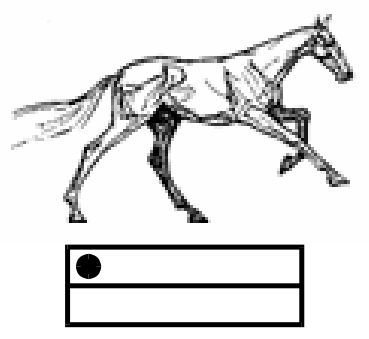

b)

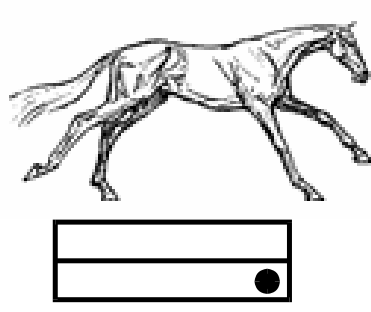

c)

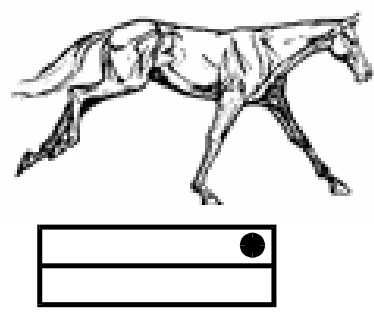

d)

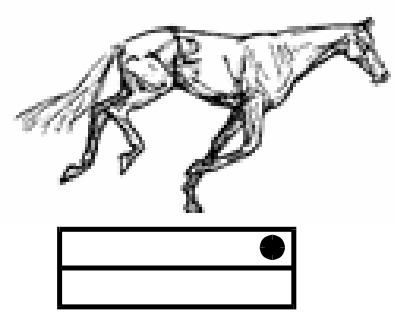

e)

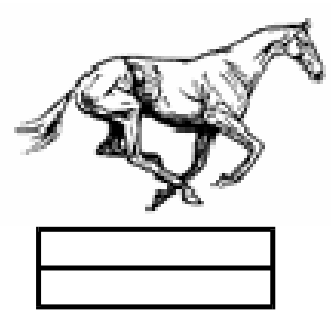

f)

Figure 19. Movements of limbs in a four legs gallop with footfall formulas representation (black circles stands for the limbs in contact with the ground surface): a) first beat; b) second beat; c) third beat; $d$ ) fourth beat; e) preparing for the suspension phase; f) suspension phase (all feet are off the ground) 
Also the choice of the most convenient gait and the transition from a gait to another can be a difficult task for systems having a high number of limbs. These aspects are crucial issues when one try to mimic animal or insect like gaits.

\section{Low-Cost Designs at LARM in Cassino}

A challenge for a practical use of walking machines both in industrial and non-industrial environments can be recognized in the development of design solutions and operation modes with low-cost easy-operation features. This is the approach that has been and still is used at LARM to develop projects, experiences, and teaching on walking machines. In this section those aspects are illustrated to show the feasibility of carrying out activity on walking machines at any level of expertise and fund compatibility.

At LARM activity on walking machines has been addressed to biped robots and modular leg designs with low-cost components and easy-operation via PLC programming. Three prototypes are illustrated: EP-WAR, 1dof leg, and leg module.

Each leg mechanism of EP-WAR, shown in Fig.20, is composed by a pantograph and a double articulated parallelogram. The pantograph has the fundamental function to transmit the trajectory of foot point $\mathrm{C}$ to the actuation point $\mathrm{H}$ and reduce the movement size. The pantograph proportions give same kinematic proprieties between the points $\mathrm{H}$ and $C$ of Fig. $20 \mathrm{~b}$ ), with a scaling factor equal to 4 . The parallelogram mechanism ensures a pure translation of the foot in a vertical plane. A complex control for legs co-ordination and dynamic stability has been avoided by using suction-cups beneath the feet to obtain static walking. Thus, EP-WAR can follow general polygonal trajectory in the plane of the motion because of a suitable mechanical design of each ankle joint with an axial ball bearing and a pneumatic rotation actuator.

In order to mimic the human gait, a suitable path is required for $C$ foot point. The foot path is imposed through the actuation point $\mathrm{H}$ by using the scale factor 4 of the pantograph mechanism.
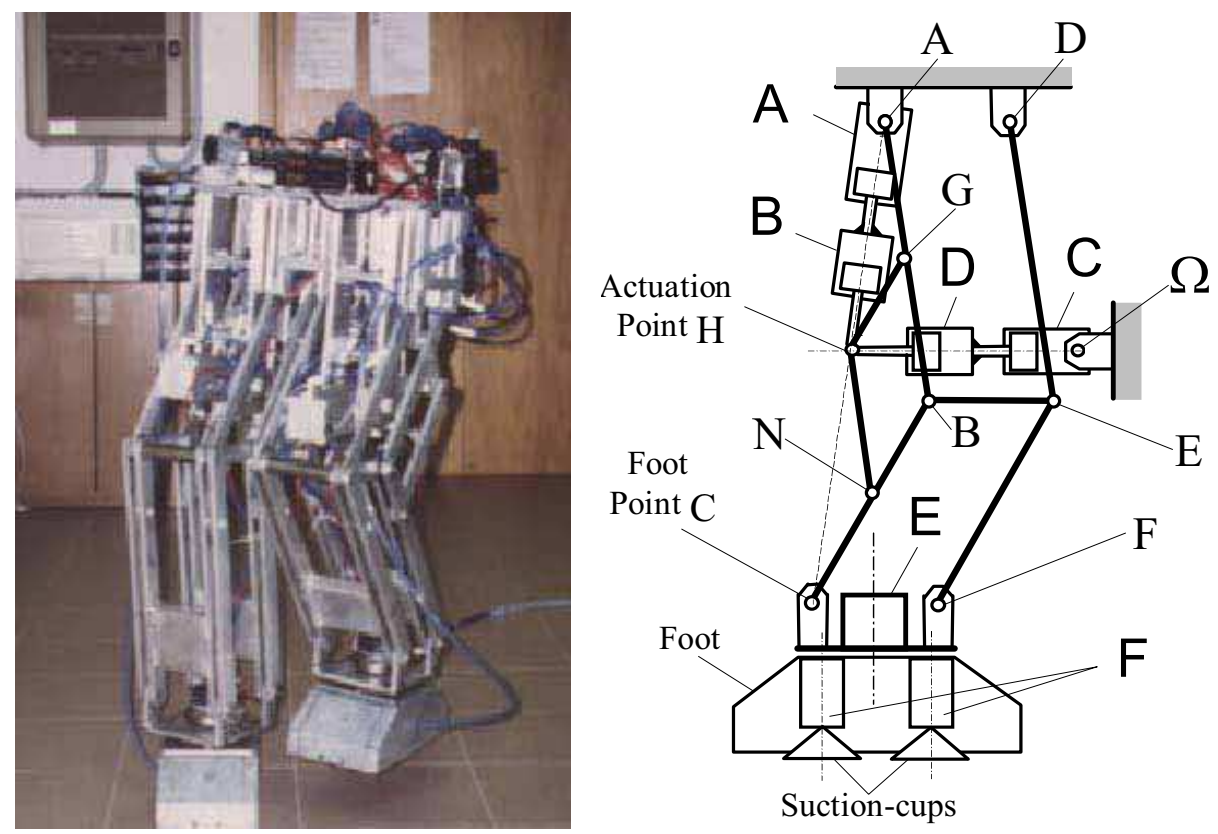

Figure 20. EPWAR (ElectroPneumatic WAlking Robot) built at LARM in Cassino: a) a prototype; b) a diagram for the leg design 
A linear actuator $\mathrm{A}$ is connected to the body frame and actuation point $\mathrm{H}$ through revolute joints so that it is parallel to the terrain when the foot is at the start or end position.

Other two linear actuators B have been installed and connected both to the robot body and actuation point $\mathrm{H}$ through revolute joints. The operation of the proposed actuation system for each leg mechanism determines a trajectory of the actuation point $\mathrm{H}$ and consequently of the C foot point. The trajectory of EP-WAR foot can be even different to egg-shaped path of the human foot.

The trajectory of $\mathrm{H}$ gives a path of the foot, which is characterized by a forward displacement of half step $\mathrm{p} / 2$ length and a foot rise of height $\mathrm{h}$. In addition the imposed trajectory permits an easy control of the actuation system in an On/Off environment via PLC. A controlled operation can be obtained through four phases: the first one corresponds to the in stroke movement of actuators $B$; the second one is related to the in stroke movement of the actuator $\mathrm{A}$; the third one gives the outstroke movement of $\mathrm{B}$; and finally the fourth phase corresponds to the outstroke movement of A.

The concept of elementary actions has been used to obtain suitable modules and subroutine programs, which can be easily combined to give any trajectory of EP-WAR. An elementary action can be defined as the smallest operation which may correspond to the simplest actuating action requiring one or few programming instructions. Additionally, it has been thought convenient and suitable to model any trajectory of a walking of EP-WAR with straight or turn paths since these kinds of motion can be easily performed by the prototype. Three walking modules and subroutine programs have been developed for straight line, right turn and left turn trajectories, respectively. They refer to a start position of EP-WAR with the right foot (a) ahead and on the ground, while the left foot (b) is free in back position. The turn walking module can be analyzed and specific sequences are reported in Figs. 21 and 22 for right turn trajectory. Referring to Fig. 21 with right foot in position (a), the first elementary action for EP-WAR is obtained by a forward and up motion of the leg from (b) to (c).

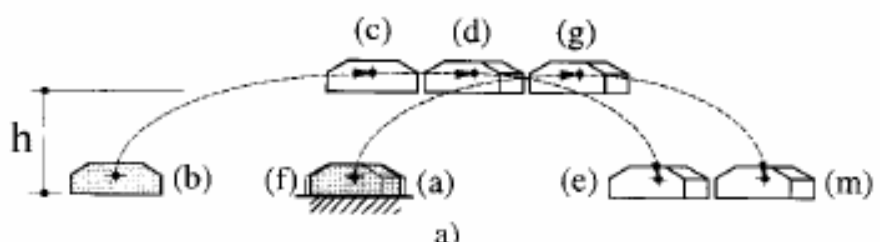

a)

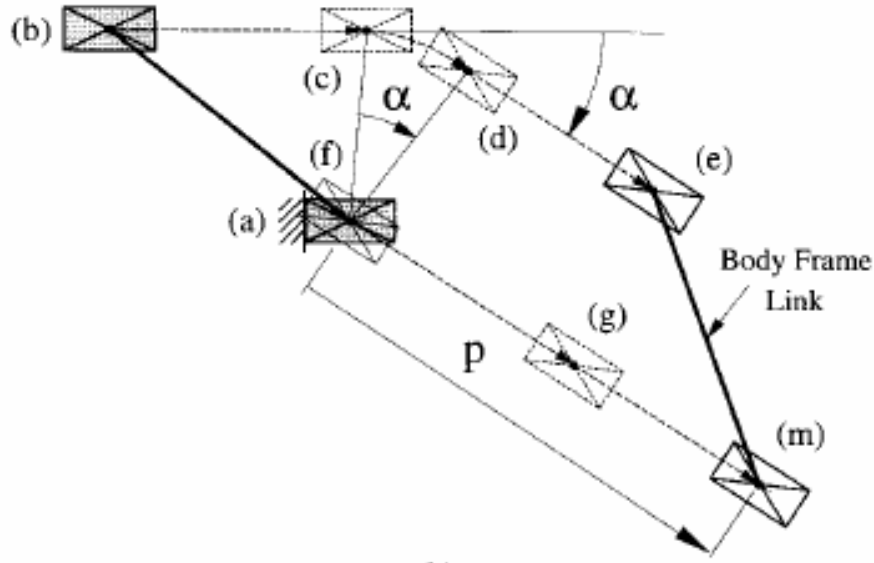

b)

Figure 21. A walking analysis for a module of right turn trajectory of EP-WAR by using elementary actions: a) Sagittal view; b) Top view 
The second action is performed for right turn of an angle a about vertical axis across the right foot.

Thus the left foot turns from (c) to (d) and then it is moved to the ground in (e). Successively the suction-cups of the left foot that is in (e) are operated and those of the right foot that is in (a) are switched-off so that the ground contact is moved from one foot to the other. Then the right foot turns from (a) to (f) and becomes parallel to the left foot. Successively it moves forward and up from (f) to (g) and finally to $(\mathrm{m})$. This right turn module ends when the suction-cups of the right foot in $(\mathrm{m})$ are operated again and those of the left foot in (e) are switched-off. Thus the EP-WAR reaches the start position again and a next walking module can be performed. The corresponding diagrams for a suitable flexible programming in a sub-routine for PLC is reported in Fig.22.

The length $L$ of a general straight path can be given by a q value so that

$$
L=q^{*} p
$$

and the subroutine represented by Fig.7b) is repeated until the counter variable $\mathrm{q}$ is equal to $\mathrm{q}^{*}$.

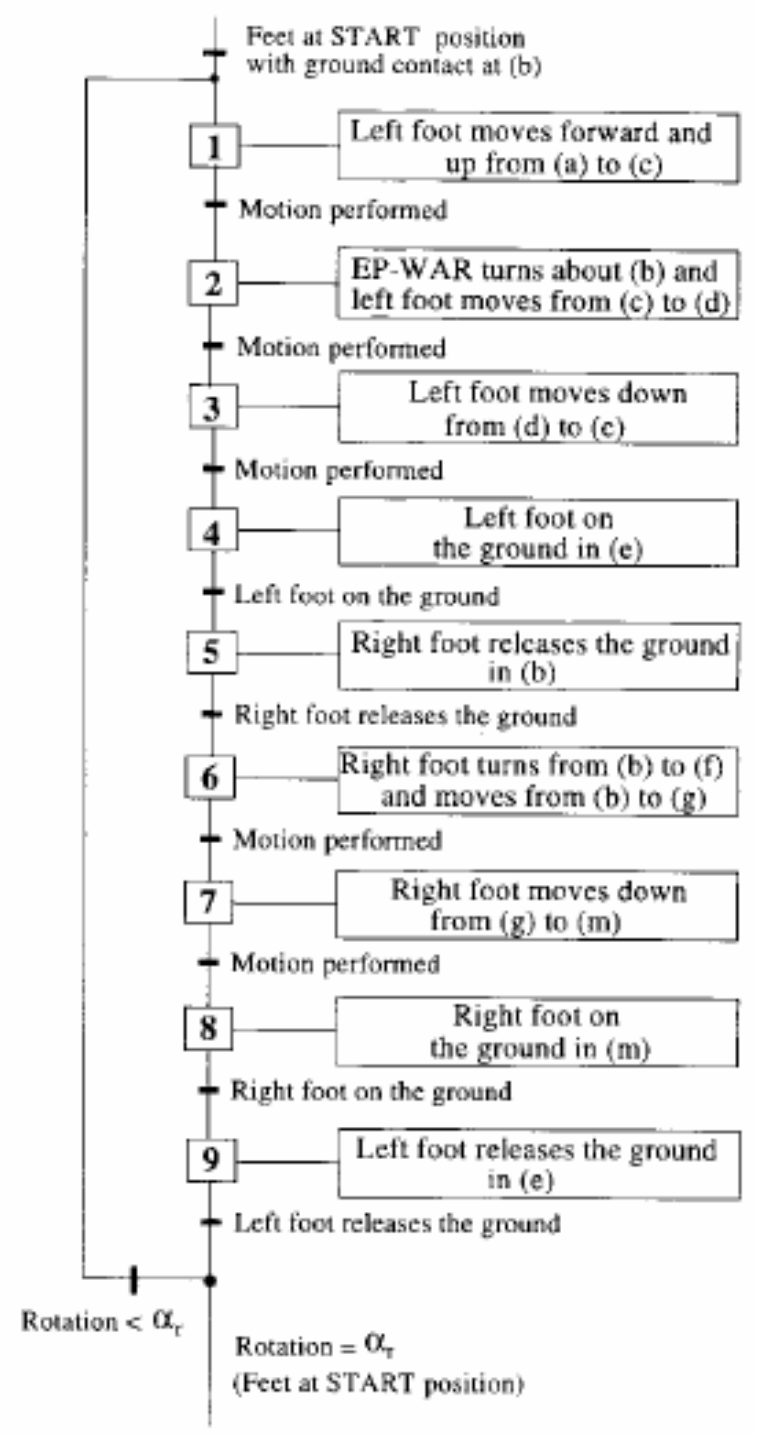

a)

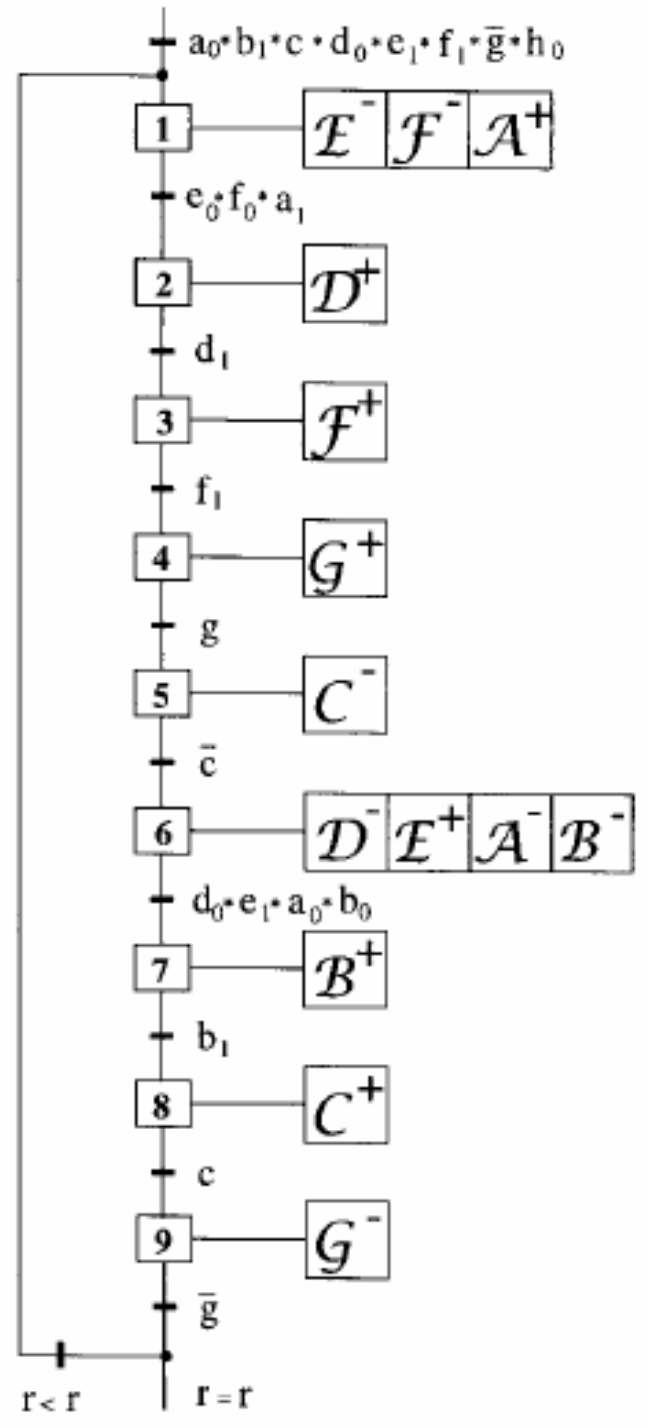

b)

Figure 22. Flowcharts for easy programming of the right turn walking module of Fig. 21: a) Sequences of the elementary actions; b) Grafcet diagram 
Similarly, the turning displacement of the walking robot can be performed to the right or to the left by using the corresponding Grafcet diagrams to be repeated $r^{*}$ and $s^{*}$ times. In order to obtain a right turn angle equal to

$$
\alpha_{\mathrm{r}}=\mathrm{r}^{*} \alpha
$$

or similarly for a left turn angle with $\mathrm{s}^{*}$, where $\alpha$ is the module angular turn corresponding to a step displacement. The modular angular turn is determined by the rotation capability of the rotative cylinders so that the radius $R$ of the turn is fixed and equal to

$$
\mathrm{R}=\frac{\mathrm{p}}{2 \sin \frac{\alpha}{2}}
$$

Finally, a general programming for a generic trajectory can be easily obtained by using the abovementioned sub-routines and a user will only assembly a suitable number of each sub-routines to achieve a desired trajectory of the walking robot. The control of the walking robot in a digital environment has been obtained by using a commercial PLC. The central unit can be connected as a remote terminal of the PLC with a common Personal Computer through a serial port RS-232 for an off-line programming, even for updating the sub-routines when additional features are provided to EPWAR.

At LARM the abovementioned approaches has been extended to design new leg systems with better features both in term of low-cost properties and easy operation programming. Basic considerations for a low-cost leg design can be outlined as follows: the leg should generate an approximately straight-line trajectory for the foot with respect to the body; the leg should have an easy mechanical design; if it is specifically required it should posses the minimum number of DOFs to ensure the motion capability. Among many different structures, at LARM the so-called Chebyshev-pantograph leg has been developed. The proposed leg mechanism is shown in Fig.23. Its mechanical design is based on the use of a Chebyshev four-bar-linkage, a five-bar linkage, and a pantograph mechanism. For such a mechanism, the leg motion can be performed by using 1 actuator only. The leg has been designed by considering compactness, modularity, light weight, reduced number of DOF as basic objectives to achieve the walking operation.

Numerical and experimental results show that good kinematic features can be obtained when points $C$ and $P$ in Fig. 23 are not coincident. The main characteristic of the proposed leg design consists in a fully-rotative actuation at point L to obtain the suitable trajectory of point $B$ with one motor only that run continuously without any speed regulation. Furthermore, the trajectory of point $\mathrm{B}$, and consequently, point A can be suitably modified by changing the design parameters shown in Fig. 23b). In particular, better features can be obtained if the transmission angles $\gamma_{\text {? }}$ and $\gamma_{2}$ have suitable values.

Dimension of the leg prototypes are $400 \mathrm{~mm}$ high, $40 \mathrm{~mm} \times 250 \mathrm{~mm}$ so that they have a maximum lift of $80 \mathrm{~mm}$ and the step is of $470 \mathrm{~mm}$.

In Figs. 24 and 25 the basic operation features of the Chebyshev-pantograph leg mechanism are reported through simulation results to show the feasibility of the low-cost easy operation design that have been experienced successfully by using a commercial DC motor without motion control equipment.

At LARM a so-called modular anthropomorphic leg has been obtained by defining a single link module that can be easily connected with other modules and can have inside all the needed actuators, transmissions and sensors. Figure 26 shows the proposed design for 
a single link module by using conic gears or timing belt transmissions. The main components of a single link module are:

- the body of the module;

- a dc motor with reduction gear train;

- two conic gears or a timing belt transmission;

- two mechanical switches.

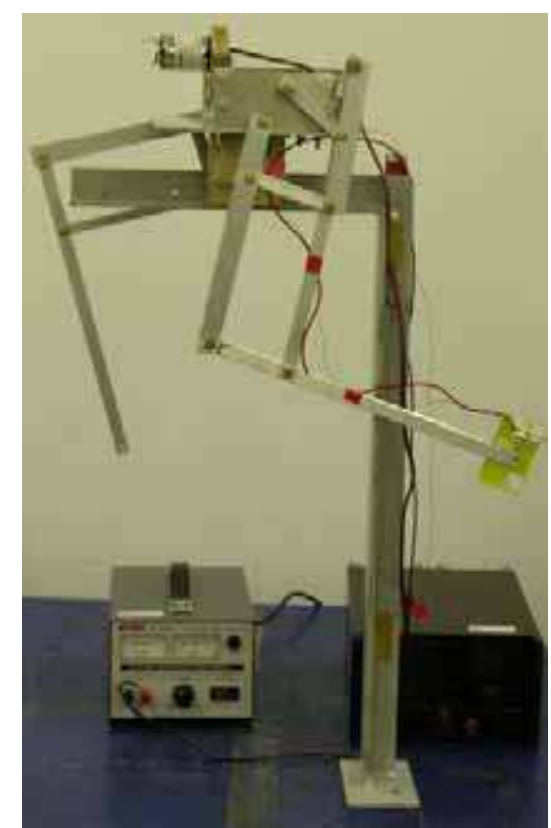

a)

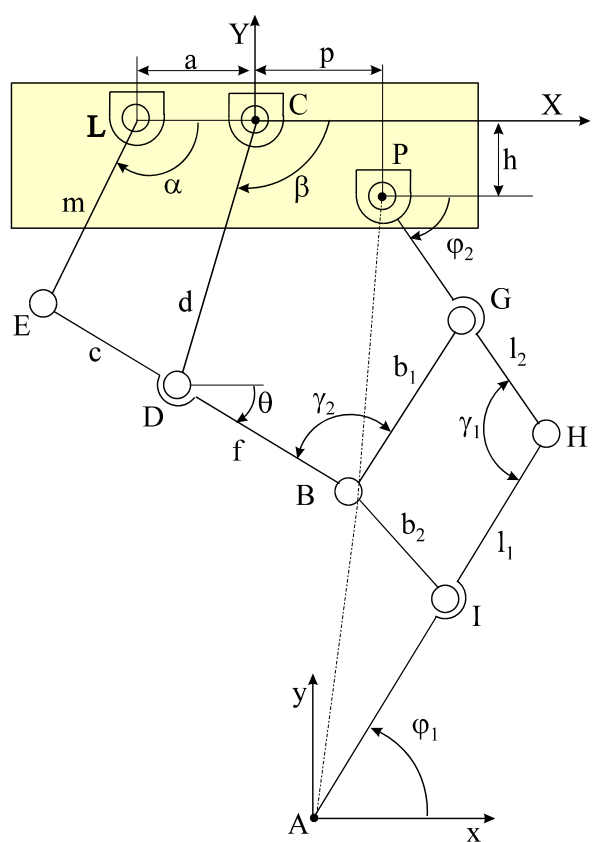

b)

Figure 23. The so-called Chebyshev-pantograph leg developed at LARM: a) a first prototype; b) a kinematic diagram

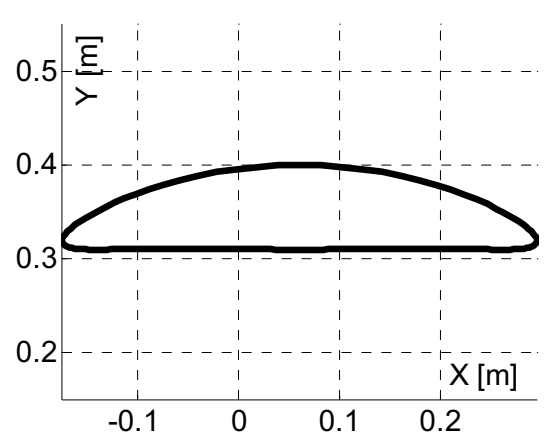

a)

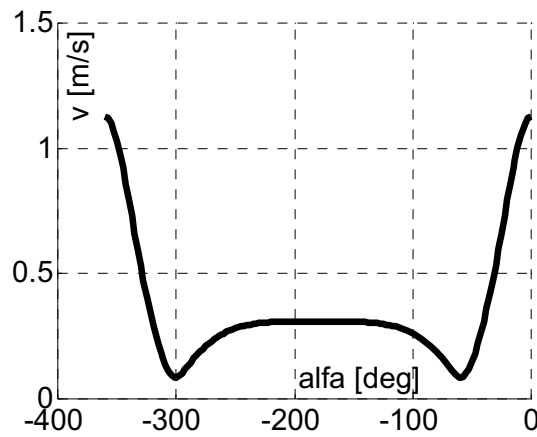

b)

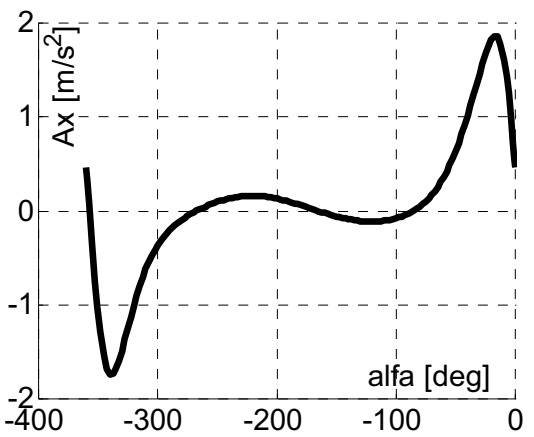

c)

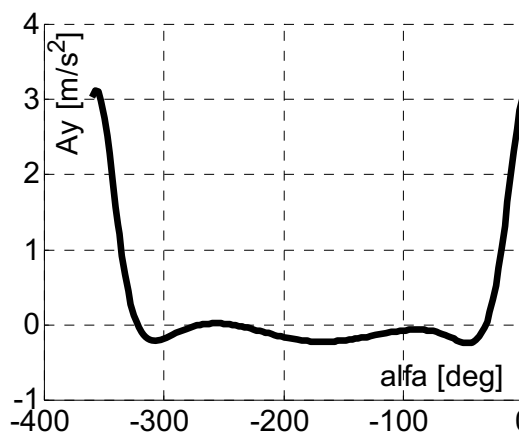

d)

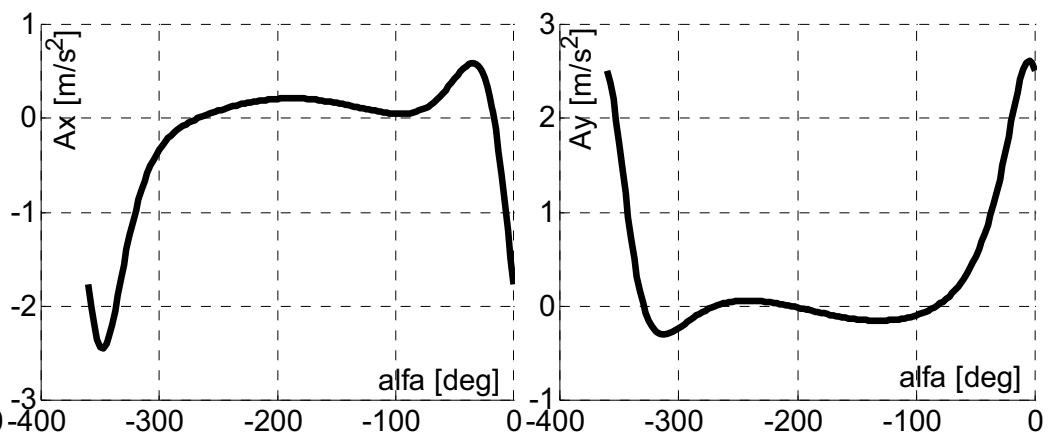

e)

f)

Figure 24. Simulation for the walking characteristics of the 1-DOF leg in Fig. 23 with $p=20 \mathrm{~mm}$ and $\mathrm{h}=-30$ mm: a) Point $\left(\right.$ trajectory; b) Point A velocity; c) Acceleration $a_{A x}$; d) Acceleration $a_{A Y}$; e) Acceleration $a_{A x} ; f$ ) Acceleration $\mathrm{a}_{\mathrm{Ay}}$ 


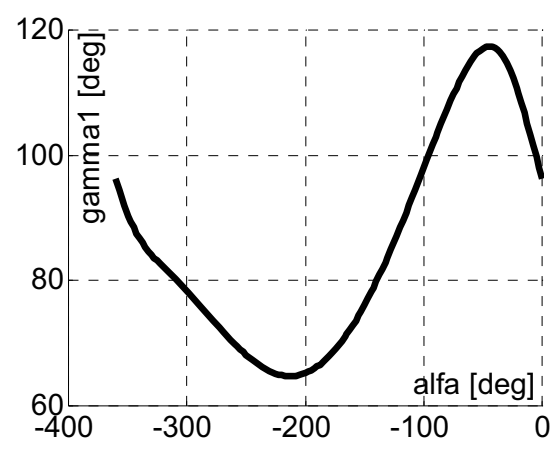

a)

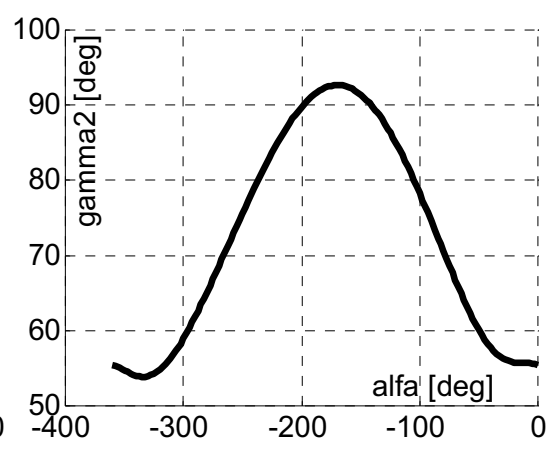

b)

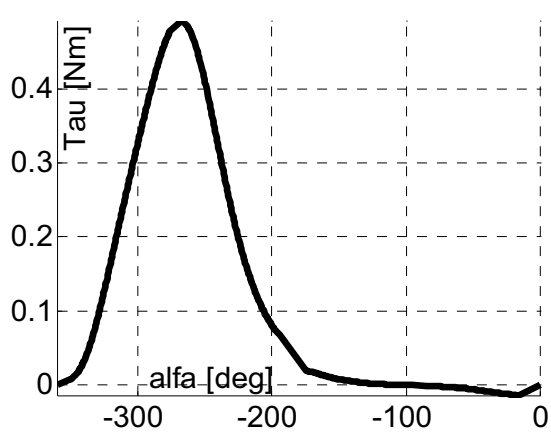

c)

Figure 25. Simulation for the walking characteristics of the 1-DOF leg in Fig. 23 with $p=20 \mathrm{~mm}$ and $\mathrm{h}=-30$ mm: a) Transmission angle $\gamma_{1}$; b) Transmission angle $\gamma_{2}$; c) actuating torque $\tau$

It is worth noting that the number of link modules can be decided according with the needed number of degrees of freedom. The link modules can be also properly oriented with respect to the others in order to achieve the required pitch, jaw or roll motions. A link module can be also easily modified in order to drive a wheel.

Dimension of the built prototype leg that is composed by 3 modules and one wheel in the foot, is high $500 \mathrm{~mm}$ and has a cross-section of $60 \mathrm{~mm} \times 60 \mathrm{~mm}$. the built leg prototype in Fig. 26 has a maximum lift of $155 \mathrm{~mm}$ and the step is of $310 \mathrm{~mm}$. Maximum rotation for each joint is +/- 90 deg.

In Fig. 27 the programming of walking is reported through the scheme of the analysis of elementary actions and corresponding Grafect to use a PLC that will control the operation of the actuators by using signals by suitable switches for the leg mobility. In Fig.28 an example is shown of using the leg for an hexapod design that has been simulated and is under construction at LARM with low-cost easy-operation features.

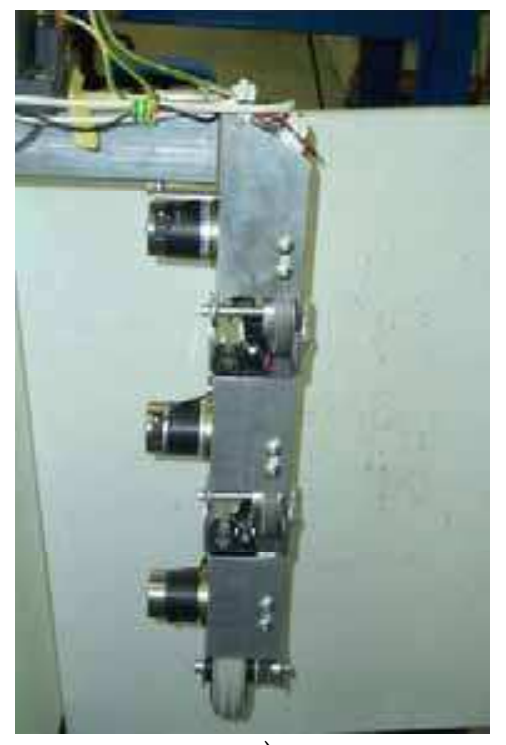

a)

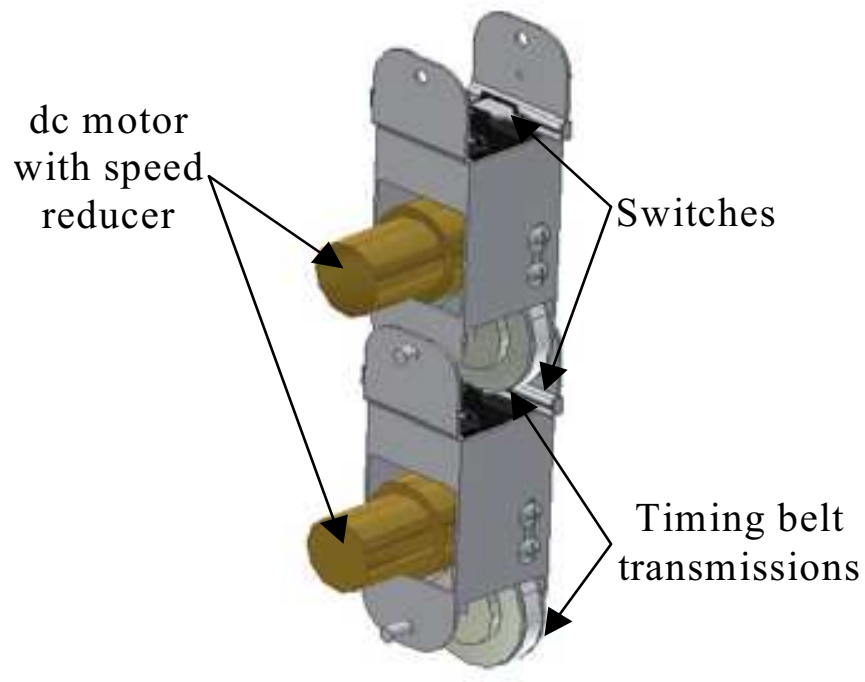

b)

Figure 26. The so-called modular anthropomorphic leg developed at LARM: a) a built prototype; b) the mechanical design 


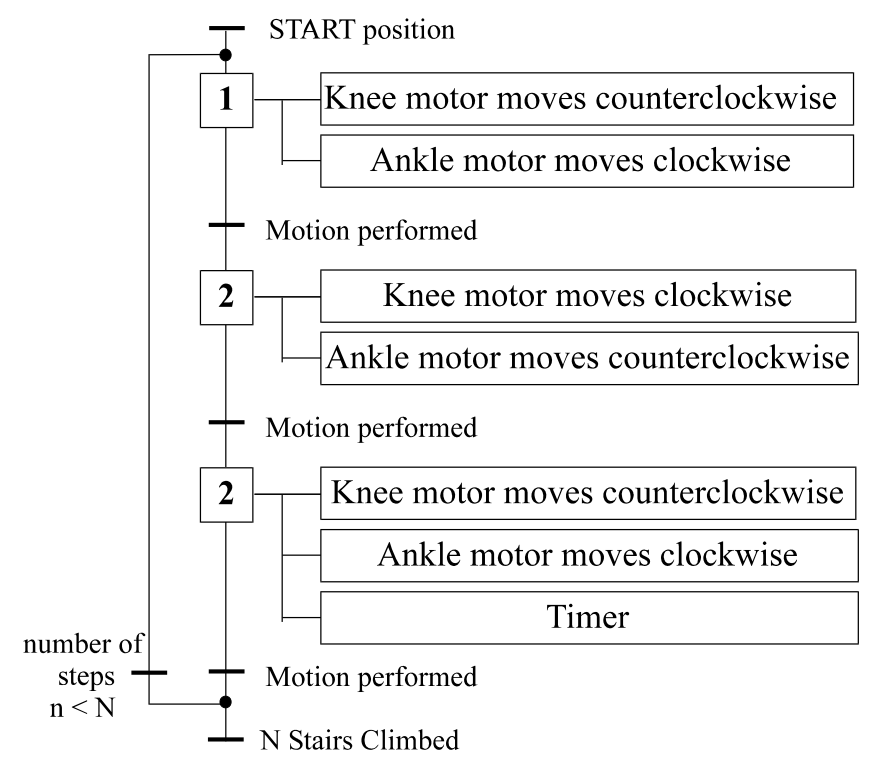

a)

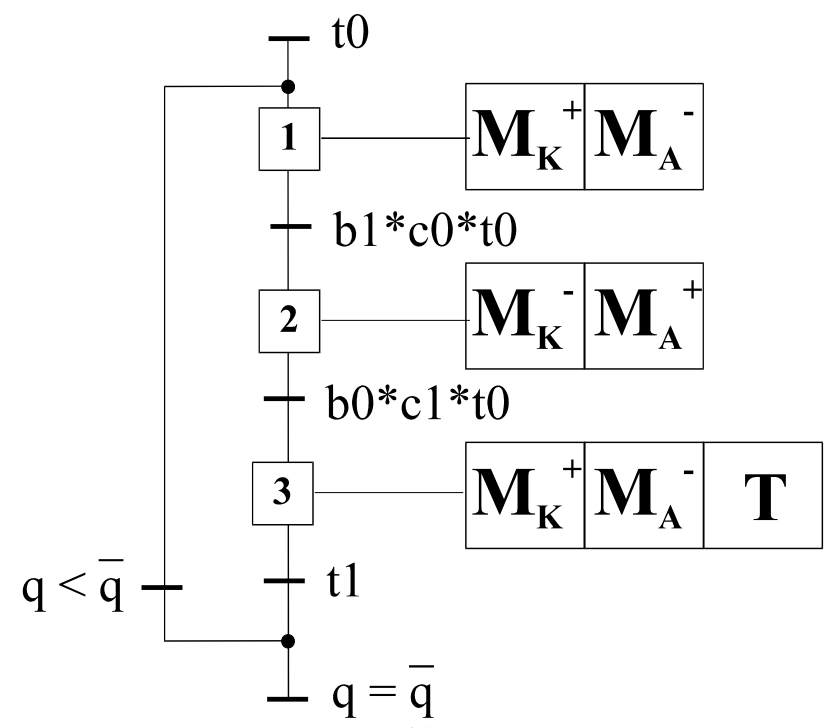

b)

Figure 27. An example of the operation programming for the proposed low-cost anthropomorphic wheeled leg in Fig.26 for the straight walking: a) flowchart of elementary actions; b) Grafcet for PLC programming
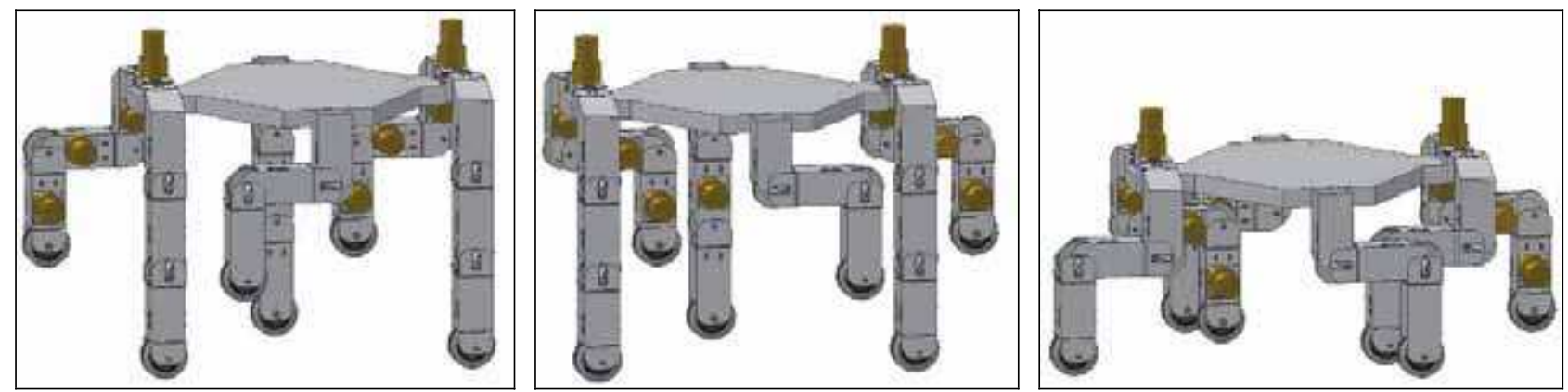

Figure 28. An application of the proposed low-cost modular anthropomorphic leg for hexapod walking machines

\section{Conclusions}

The variety of currently available walking machines gives many solutions to the problem of artificial walking for many applications. Combining properly suitable designs of 
mechanical architectures, actuator systems, sensors equipment can give walking machines with very good characteristics and performances that can make prototypes very promising and even already available in the market. However, the challenge for future assessment of walking machines as convenient transportation machinery can be recognized in the development of low-cost easy-operation systems whose designs try to mimic the legged systems in nature but overpassing their performances and reducing their complexity in functionality.

\section{References}

Technical and scientific literature on walking machines is very reach in terms of Conference and Journal papers, monographs, and books. Since space limits and the introductory character of this manuscript, we have limited the reference list to the main sources for information and further reading.

Active Structures Laboratory, Université Libre de Bruxelles, http://www.ulb.ac.be/ scmero/robotics.html, 2005.

Aibo Europe homepage, http://www.aibo-europe.com/, 2005.

Ambulatory Robotic Lab., http:/ /www.cim.mcgill.ca/ arlweb/, 2005.

Androidworld homepage, http://www.androidworld.com, 2005.

Ceccarelli M., "Fundamentals of Mechanics of Robotic Manipulation", Kluwer Academic Publishers, Dordrecht, 2004.

Control and Robotics Lab., Chiba University, http:/ / mec2.tm.chiba-u.jp/ nonami/, 2005.

Dickinson M.H., Farley C.T., Full R.J., Koehl M.A., Kram R., Lehman S., “How Animals Move: An Integrative View", Science, Vol.288, pp.100-106, 2000.

Figliolini G., Ceccarelli M., "Walking Programming for an Electropneumatic Biped Robot", Journal of Mechatronics, Vol.9, pp.941-964, 1999.

Gonzalez de Santos P., Jimenez M.A., Armada M.A., “Dynamic Effects in Statically Stable Walking Machines", Journal of Intelligent and Robotic Systems, Vol.23, n.1, pp. 71-85, 1998.

Harris S.E., "Horse Gaits, Balance and Movement", Howell Reference Books, New York, 1993.

Hirose \& Yoneda Robotic Lab., Tokyo Institute of Technology, http://wwwrobot.mes.titech.ac.jp/home_e.html, 2005.

Industrial Automation Institute of CSIC in Madrid, http://www.iai.csic.es/users/gds/ web1c2.htm\#rimho, 2005.

Iagnemma K., Dubowsky S., "Mobile Robots in Rough Terrain. Estimation, Motion Planning, and Control with Aplication to Planetary Rovers", Springer Verlag, Berlin, 2004.

Intelligent Machines and Special Robotics Institute, Helsinki University of Technology, http://www.automation.hut. fi/IMSRI/ workpartner/, 2005.

Joker Robotics, http://www.joker-robotics.com/walker/, 2005.

LARM: Laboratory of Robotics and Mechatronics, University of Cassino, http://webuser.unicas.it/weblarm/larmindex.htm, 2005.

Ottaviano E., Lanni C., Ceccarelli M., "Numerical and Experimental Analysis of a Pantograph-Leg with a Fully-Rotative Actuating Mechanism", 11th World Congress in Mechanism and Machine Science IFToMM2004, pp.1537-1541, 2004.

Plustech Ltd., http:/ / www.plustech.fi/Plmain01.html, 2005.

Research Group IDS, Center of Research FZI, http://www.fzi.de/ids/eng/ projekte.php?id=18, 2005. 
Salmi S., Halme A., "Implementing and testing a reasoning-based free gait algorithm in the six-legged walking machine Mecant" Control Engineering Practice, Vol. 4, n.4, pp. 487-492, 1996.

Walking Machine Catalogue, http:/ / www.walking-machines.org/, 2005.

Zhao Y.S., Lu L., Zhao T.S., Du Y.H., Huang Z., "Dynamic performance analysis of sixlegged walking machines" Mechanism and Machine Theory, Vol. 35, n.1, pp. 155-163, 2000.

Zielinska T., Heng J., 'Development of a walking machine: mechanical design and control problems", Mechatronics, Vol.12, n.5, pp.737-754, 2002. 


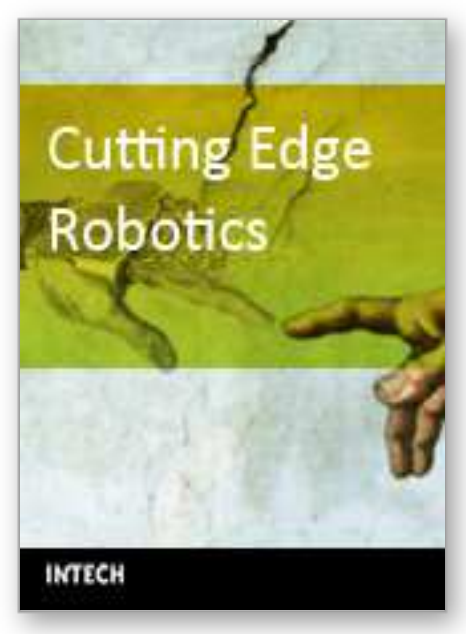

\section{Cutting Edge Robotics}

Edited by Vedran Kordic, Aleksandar Lazinica and Munir Merdan

ISBN 3-86611-038-3

Hard cover, 784 pages

Publisher Pro Literatur Verlag, Germany

Published online 01, July, 2005

Published in print edition July, 2005

This book is the result of inspirations and contributions from many researchers worldwide. It presents a collection of wide range research results of robotics scientific community. Various aspects of current research in robotics area are explored and discussed. The book begins with researches in robot modelling \& design, in which different approaches in kinematical, dynamical and other design issues of mobile robots are discussed. Second chapter deals with various sensor systems, but the major part of the chapter is devoted to robotic vision systems. Chapter III is devoted to robot navigation and presents different navigation architectures. The chapter IV is devoted to research on adaptive and learning systems in mobile robots area. The chapter V speaks about different application areas of multi-robot systems. Other emerging field is discussed in chapter VI - the human- robot interaction. Chapter VII gives a great tutorial on legged robot systems and one research overview on design of a humanoid robot. The different examples of service robots are showed in chapter VIII. Chapter IX is oriented to industrial robots, i.e. robot manipulators. Different mechatronic systems oriented on robotics are explored in the last chapter of the book.

\section{How to reference}

In order to correctly reference this scholarly work, feel free to copy and paste the following:

Giuseppe Carbone and Marco Ceccarelli (2005). Legged Robotic Systems, Cutting Edge Robotics, Vedran Kordic, Aleksandar Lazinica and Munir Merdan (Ed.), ISBN: 3-86611-038-3, InTech, Available from: http://www.intechopen.com/books/cutting_edge_robotics/legged_robotic_systems

\section{INTECH}

open science | open minds

\author{
InTech Europe \\ University Campus STeP Ri \\ Slavka Krautzeka 83/A \\ 51000 Rijeka, Croatia \\ Phone: +385 (51) 770447 \\ Fax: +385 (51) 686166 \\ www.intechopen.com
}

\author{
InTech China \\ Unit 405, Office Block, Hotel Equatorial Shanghai \\ No.65, Yan An Road (West), Shanghai, 200040, China \\ 中国上海市延安西路65号上海国际贵都大饭店办公楼 405 单元 \\ Phone: +86-21-62489820 \\ Fax: +86-21-62489821
}


(C) 2005 The Author(s). Licensee IntechOpen. This chapter is distributed under the terms of the Creative Commons Attribution-NonCommercial-ShareAlike-3.0 License, which permits use, distribution and reproduction for non-commercial purposes, provided the original is properly cited and derivative works building on this content are distributed under the same license. 